IZA DP No. 6518

Private and Public Provision of Counseling to Job-Seekers:

Evidence from a Large Controlled Experiment

Luc Behaghel

Bruno Crépon

Marc Gurgand

April 2012 


\title{
Private and Public Provision of Counseling to Job-Seekers: Evidence from a Large Controlled Experiment
}

\author{
Luc Behaghel \\ Paris School of Economics (INRA), \\ CREST and IZA \\ Bruno Crépon \\ CREST and IZA \\ Marc Gurgand \\ Paris School of Economics (CNRS), \\ CREST and IZA
}

Discussion Paper No. 6518

April 2012

IZA

P.O. Box 7240

53072 Bonn

Germany

Phone: +49-228-3894-0

Fax: +49-228-3894-180

E-mail: iza@iza.org

Any opinions expressed here are those of the author(s) and not those of IZA. Research published in this series may include views on policy, but the institute itself takes no institutional policy positions.

The Institute for the Study of Labor (IZA) in Bonn is a local and virtual international research center and a place of communication between science, politics and business. IZA is an independent nonprofit organization supported by Deutsche Post Foundation. The center is associated with the University of Bonn and offers a stimulating research environment through its international network, workshops and conferences, data service, project support, research visits and doctoral program. IZA engages in (i) original and internationally competitive research in all fields of labor economics, (ii) development of policy concepts, and (iii) dissemination of research results and concepts to the interested public.

IZA Discussion Papers often represent preliminary work and are circulated to encourage discussion. Citation of such a paper should account for its provisional character. A revised version may be available directly from the author. 


\section{ABSTRACT}

\section{Private and Public Provision of Counseling to Job-Seekers: Evidence from a Large Controlled Experiment ${ }^{*}$}

Contracting out public services to private firms has ambiguous effects when quality is imperfectly observable. Using a randomized experiment over a national sample in France, we compare the efficiency of the public employment service (PES) vs. private providers in delivering very similar job-search intensive counseling. The impact of each program is assessed with respect to the standard, low intensity track offered by the PES to the unemployed. We find that job-search assistance increases exit rates to employment by 15 to $35 \%$. But the impact of the public program is about twice as large as compared to the private program, at least during the 6 first months after random assignment. We argue that the observed contract structure with the private providers has not overcome the underlying agency problem. We find no evidence of cream-skimming: rather, it seems that profit maximizing private providers have found it optimal to enroll as many job-seekers as they could, but to make minimum effort on the placement of some of them.

JEL Classification: J64, J68, H44

Keywords: unemployment, job-search assistance, labor market intermediaries, private provision of public services

Corresponding author:

Luc Behaghel

Paris School of Economics

48, boulevard Jourdan

75014 Paris

France

E-mail: luc.behaghel@ens.fr

\footnotetext{
This paper benefited from comments by Katya Zhuravskaya, Sylvie Lambert, Thomas Le Barbanchon, Thomas Piketty and seminar participants at INSEE, Evry University, Tinbergen Institute, Ecole thématique du CNRS, and Paris School of Economics. We would like to thank ANPE, Unédic and DARES for their involvement in the experiment from which the data are drawn, and for their financial support to the evaluation. In particular, we thank François Aventur, Céline Gratadour, Thomas Le Barbanchon, Béatrice Sédillot and Claude Seibel. We are grateful to Julien Guitard who contributed to the design and implementation of the experiment on the research side. We also thank Lucie Gadenne and Hélène Blake for research assistance.
} 


\section{Introduction}

Job-search counseling policies have received increasing attention both from policy makers and researchers in many countries over the last decades. Evaluations show that they are generally efficient, especially compared with more traditional active labor market policies, such as training and subsidized employment (Card et al., 2010). Until the late 1990s, OECD countries typically involved a broad range of public and semi-public education institutions as well as private firms in the training of job-seekers, while public employment agencies had a monopoly on individual assistance and the matching of job-seekers with vacancies. But the recent and rapid expansion of job-search assistance to a large number of unemployed persons has increasingly relied on publicly funded private providers (Finn, 2011). Australia (in 1998), the Netherlands (in 2001) allowed private providers to take over the individual assistance of job-seekers. Similarly, in the US, a significant minority of states started contracting out case management and eligibility determination to private providers in welfare to work programs 11 These early movers have emulated others, with a strong support of international organizations such as the OECD or the European Union (EU). In particular, in 1998, the European Commission urged EU members states to open publicly funded employment services to privates providers in order to increase efficiency ${ }^{2}$ Whether these changes actually improved the well-being of job-seekers and reduced the costs of services is the topic of highly polemical public debates ${ }^{3}$

Outsourcing public services to private firms raises classical economic issues when either actions or quality are not perfectly observable. In the job-search counseling environment, it may seem that the actions to implement are observable and can be monitored. However, the unemployed are strongly heterogeneous and the actual effort targeted to each single person is impossible to control. The fact that the effort and ability of the unemployed person (her capacity to find a job on her own) is largely unobservable limits what can be inferred from observed outcomes. As a result, cream-skimming (by which the providers

\footnotetext{
${ }^{1}$ In 1996 the Personal Responsibility and Work Opportunity Reconciliation Act gave more autonomy to individual states for implementing a new welfare program, "Temporary Assistance for Needy Families" (TANF). Several states and localities (among which Wisconsin and New York City) contracted out all services, including eligibility for TANF financial assistance and case management, to private providers. See McConnell et al., 2003.

"'It is essential to redefine the role and tasks of the PESs in relation to the other providers of commercial or non-commercial services: for example, possibility of the PESs withdrawing from activities which can be carried out more effectively by other employment services, possibility of outsourcing certain tasks" (EC, 1998).

${ }^{3}$ In France, for instance, the government's decision to outsource the case management of 320,000 jobseekers to private providers in 2010 and 2011 made the headlines of a national newspaper, titling "Making money on the back of job-seekers" (L'Humanité, 2009), while a member of parliament challenged the government stating that "The fierce competition of these firms [private providers of job-search assistance] against one another bears almost only on costs, to the greatest prejudice of the service to persons made vulnerable by the loss of a job." (Assemblée nationale, 2009)
} 
only enroll job-seekers with the best labor market prospects) and parking (consisting in a bare minimum of services for harder-to-place clients) can be optimal strategies if the incentive structure created by the payment structure does not rule them out. Agency problems may thus counterbalance the perception that market discipline induces private firms to be more efficient than the PES.

This paper provides novel empirical evidence on this issue. It analyzes one episode of the opening of the market of job-seekers' placement to private providers in France, in 2007-2008. This episode allows a direct comparison of the placement impacts of two highly comparable job-search programs, one provided in-house by the Public employment agency (ANPE), the other one outsourced to private providers by the Unemployment insurance organization (Unédic) 4 The context is as follows: In the end of 2006, the unemployment benefit (UB) fund mandates private providers to provide job-search assistance to unemployed job-seekers eligible for unemployment benefits. The stated goal is to make savings: the UI anticipates that the costs of job-search assistance will be lower than the benefits saved thanks to the job-seekers' faster exit from unemployment. An additional goal is to create competitors to the Public employment agency, just after a law passed in 2005 has abolished ANPE's monopoly on the placement of job-seekers. ANPE responds by developing a "twin" job-search program, provided in house by dedicated personal advisors (caseworkers). The two programs provide much more intensive assistance than the standard track followed by job-seekers; to that effect, in each program, the caseload ratio is limited to 40 job-seekers per personal advisor, compared to about 120 in the standard track. Even though each program is planned to serve about 40,000 job-seekers over one year, they are conceived as experimental programs and are jointly evaluated, using a randomized controlled trial. We present the results of this evaluation, implemented in about 400 local public employment branches and involving more than 200,000 job-seekers.

There are two basic results. First, intensive counseling does increase transitions to employment in the two programs. After 6 months, for instance, exit rates to employment increase by 4 to 9 percentage points for program recipients, a 15 to $35 \%$ increase given counterfactual exit rates (around 25\% under the standard track). Second, impacts are consistently higher for the public program as compared to the private one. An unexpected result is that the private program has actually no impact on the number of days in compensated employment in the year that follows assignment, implying that it incurs no reduction in unemployment insurance payment.

We also find evidence that private providers respond closely to the detailed incentives

\footnotetext{
${ }^{4}$ In the French system, the two organizations were, at the time, distinct, one being a State agency, the other a workers-employer unions ruled institution.
} 
of their contract with the UB fund. In a second part of the paper, we therefore investigate whether the incentives set to private providers may explain their lower performance. Outsourcing contracts of job-search program frequently involve a two-tier payment to the providers: an (unconditional) upfront payment when the job-seeker signs in; a (conditional) payment if the job-seeker is placed on time in an eligible job. This contract structure is aimed at balancing the risks of cream-skimming and parking. We propose a simple agency model to account for that trade-off. We find evidence that the upfront payment in our setting is large enough to induce private providers to maximize program enrollment rather than to cream-skim; they probably also have incentives to park jobseekers on which job-search assistance has limited impact. This analysis implies that the lower performance of private providers could result from the difficulty to set the right incentives.

There is a growing literature evaluating job search program $5^{5}$ but, to our knowledge, none of these papers allows a direct comparison of the effect of the public vs. private provision of the service. One paper close to our's is Bennmarker at al. (2009) who evaluate the effectiveness of contracting out employment services to private placement agencies using a randomized trial. They tend to find some positive employment effects ${ }^{6}$ but it is unclear whether these effects should be attributed to the more intensive counseling per se (independently from its provider), or whether they are due to the fact that the service was contracted out to private companies. In our experiment, we compare similar counseling practices, with similar intensities, so that the different outcomes more closely result from ownership structure. Another related paper is Krug and Stephan (2011): job-seekers are randomly assigned to a mandatory counseling program provided either by private operators or by the public employment offices in Germany. Compared to our setting, the difference is that the programs are mandatory and the evaluation does not compare to a regular counseling scheme. Consistent with our paper, the authors find that the in-house counseling program performs significantly better than the private one. However, the significant increase in exit from unemployment comes both from increases in exit to employment and in exit due to withdrawal from the labor force.

\footnotetext{
${ }^{5}$ See the meta-analysis in Card et al. (2010). Dolton and O'Neill (1996, 2002) and Blundell et al. (2004) provide evaluations for the UK; for instance, Blundell et al. (2004) find that a mandatory job search program in UK increased outflows to jobs by 20\%. Meyer (1995) and Ashenfelter et al. (2005) report results for the US. By contrast, analyzing a Dutch randomized expermiment, van den Berg and van der Klauw (2006) find no evidence that counseling and monitoring affected the exit rate to work. More recently, Rosholm (2008), Bernard and Wolf (2008) and Hägglund (2009) find positive effects for Denmark, Germany and Sweden. Autor and Houseman (2011) shows that job placement firms tend to satisfy their commitment using temporary help jobs, identifying also that this leads to a significantly lower labor market integration

${ }^{6}$ The point estimates are positive, but quite imprecise due to the low take-up rate and the limited sample size, so that only one estimate is significant at $10 \%$.
} 
This paper also relates to the vast theoretical literature (Grossman and Hart, 1986, Hart and Moore, 1990, Shleifer, 1998, Hart et al., 1997, Besley and Ghatak, 2001) that examines the implications of firm ownership in the provision of public goods or public services. Private entrepreneurs may have stronger incentives to invest in cost saving and quality enhancing technologies. However, when quality is imperfectly observable, their incentives to engage in pure cost reduction may be too strong. Robust empirical evidence of the efficiency of subcontracting public services is limited 7 We consider here a version of this general question that applies to the type of agency issue arising in the employment policy context. A few papers have investigated the impact of incentives in that context. Heckman, Heinrich and Smith (2002) analyze the impact of performance standards used to monitor (public) job training centers in the context of the Job Training Partnership Act (JTPA). They do not find much room for cream-skimming; correspondingly, Heckman and Smith (2004) find that factors beyond the control of providers (personal choices, awareness of program eligibility) explain most of the selection into program. Courty and Marschke (2004), studying the JTPA too, find evidence that job training centers game the incentives by manipulating the dates of trainees' graduation to smooth performance over good and bad years. Koning and Heinrich (2010) analyze the impact of changes in the contract set to public providers in welfare to work programs in the Netherlands. Their results suggest that cream-skimming and parking are on average limited, even though they are more significant for the subgroup of disability insurance recipients. Overall, our results corroborate the idea that the risk of cream-skimming may have been overstated, leading to contracts with suboptimal incentives. The lower performance of private providers may well have been partly written in advance in their contracts. Of course, just as Heckman et al. (2002) conclude, "Nothing in this paper says that a successful [outsourcing contract] cannot be devised". The results however, call for careful implementation, involving perhaps some more experimentation.

The next section outlines the labor market context in France in 2007 and describes the public and private programs. Section 3 presents the experiment. Section 4 gives the main findings, directly derived from the randomized setting, while section 5 explores the role of contracts in explaining the private program's lower performance. The following section discusses the results, and the last section concludes.

\footnotetext{
${ }^{7}$ Notable exceptions are Hart et al.(1997) on prisons, or Duggan (2000) in health - see also the survey by McClellan (2011).
} 


\section{The programs}

Since the 1980s, the French labor market has been characterized by high unemployment rates and persistent long-term unemployment. At the beginning of the two programs, unemployment was decreasing but $8.4 \%$ of the labor force was still unemployed; among them, about $30 \%$ had been unemployed for a year or more.

Before 2005, the French public employment agency (ANPE) had a monopoly on the placement of unemployed job-seekers. The Social Cohesion Act (loi de cohésion sociale, January 2005) opened this market to private companies. In 2005-2006, the French unemployment benefit provider (Unédic) started experimenting with supplying intensive counseling to unemployment benefit claimants who had a high statistical risk of longterm unemployment. Private firms provided the counseling. In 2007, Unédic decided to scale this program up, targeting 41,000 job-seekers among those eligible for at least a year of unemployment benefits. In what follows, we call this program the "private program"; its main characteristics are as follows. Each job-seeker receives intensive counseling during up to six months. Private companies are selected through a bidding process, conducted separately in 16 geographical areas. The 11 private providers eventually selected belong to three groups: temporary agencies, consultancies specialized in the placement of workers after mass layoffs, and international firms specialized in the placement of job-seekers coming from Australia or the Netherlands. The payment structure is common to all areas: $30 \%$ of the maximum payment is paid upfront, when the job-seeker is enrolled in the program; the remaining $70 \%$ is conditional on placement: $35 \%$ is paid if the job-seeker finds a job within six months, and the remaining $35 \%$ is paid if the worker is still employed after 6 months. The maximum payment per worker results from the bidding process: it varies from one bidding area to the other, between 3,000 and 3,947 euros (Vives, 2009). In other words, the minimum payment per worker is 900 euros (the upfront payment when the job-seeker is not placed within six months), and the maximum payment is 3,947 euros (when the worker is durably placed in a job, in areas with the highest bidding price). There are restrictions upon jobs that trigger the conditional part of the payment: the contract must have an indefinite duration or, if it is a fixed-term contract, the term must be at least six months. Moreover, the working time must exceed 110 hours per month. Unédic's involvement in the placement of job-seekers is explicitly motivated by budgetary reasons: the goal is to save on benefits by quickly placing job-seekers at risk of long-term unemployment. Simultaneously but separately, the French employment public agency (ANPE) decides to launch its own in-house program of intensive counseling. In addition to the population targeted by Unédic, this program also targets job-seekers who are not eligible for unemployment benefits. Each job-seeker is also to receive intensive counseling 
during up to six months and the target is to start the program with 40,000 job-seekers in 2007. In what follows, ANPE in-house program is called the "public program".

From a political economy perspective, it is noteworthy that the public program was triggered by the new competition of the private sector. In 2006, Unédic claimed that the local experiments conducted with private companies in 2005-2006 had been highly successful. The only evidence provided for this claim was that placement rates were high. However, no proper evaluation was conducted and the take-up in these early programs was low: only $30 \%$ of the job-seekers sent to the private companies actually entered the counseling program. Selection bias was an obvious problem. These dubious results were nonetheless used by Unédic as an argument in the latent conflict against ANPE, which was accused of being inefficient. This motivated the requirement to run a randomized controlled trial to get transparent results - a première in the evaluation of labor market policies in France.

The exact content of the public and private programs varies locally. However the basic structure is the same everywhere and across the two programs. The key feature is to assign a dedicated "personal advisor" with a much lower caseload to the job-seeker; in short, more human ressources and a more integrated follow-up. This translates into at least a weekly contact (email, phone) and a monthly face-to-face meeting between the job-seeker and the caseworker. In the private program, the terms of reference imply that a caseworker may not assist more than 40 job-seekers; this is also the average caseload ratio in the public program. Compared to the usual track, where a contact is supposed to take place every month and where ANPE agents assist on average 120 job-seekers, this is a significant increase in human resources dedicated to assist the job-seeker. In addition to using similar inputs, the two programs share a common approach and similar tools aiming at empowering the job-seeker 8 Job-seekers are enrolled by signing a charter, and the 6-month trajectory within the program is organized around an individual action plan whose objective are periodically reviewed 9

One way to quantify the treatment received by the recipients of the two programs (beyond the dramatic decrease of caseload ratios) is a survey run by the Ministry of Labor on a subsample of 9,000 unemployed from the inflow that were subject to the random

\footnotetext{
${ }^{8}$ Capelier and Mizrahi (2008) conduct a qualitative comparison of the two programs, finding very few differences in methods and principles. According to another qualitative study by Divay (2009), the methods used by private providers in the private program are not particularly innovative, compared to what the PES has been doing since the 1990s. What is however new is the intensity of the two programs.

${ }^{9}$ Formally, and in contrast to comparable job search experiments in the US (Meyer, 1995; Ashenfelter, Ashmore and Deschênes, 2005), the treatments do not directly include stricter enforcement of search requirements, even though the more frequent interactions with caseworkers may be viewed as increased monitoring. We come back to the consequences of this point for the private program below.
} 
assignment 4 to 6 months after the start of the experiment. They were interviewed by telephone in March 2008, that is 11 to 9 months after their assignment. Gratadour and Le Barbanchon (2009) document that intensive counseling does increase meetings frequency, access to job offers and training program, as compared to the standard track. Table 1, made out of their figures, details the contrasts between the two providers. Generally, they are very similar. If anything, private firms tend to deliver rather more intensive service: they start meeting the job-seekers sooner after registration, and meet them more often. $64 \%$ report several meetings per month against $42 \%$ for the public program. Furthermore, private providers offer more formal training programs related to job-search practices, by typically 10 to 15 more percentage point: 10 . The only contrast in the opposite direction lies in the number of job offers that the caseworker presented to the program recipient: only $20 \%$ report having access to no job offer in the public scheme vs. $36 \%$ in the private scheme, and $42 \%$ vs. $29 \%$ report that 6 or more job offers were presented to them. We discuss this fact in more depth in section 6 below.

\section{Experimental design}

The public and the private programs were evaluated jointly in a randomized controlled trial. ${ }^{11}$ The populations concerned by the two programs partially overlap. As opposed to Unédic that decided to restrict the program to job-seekers entering unemployment and entitled to at least a year of benefits, ANPE decided to also offer intensive counseling to two other groups: the newly unemployed who were entitled to benefits for less than a year; and the long-term unemployed. Moreover, the two programs were not developed exactly in the same regions: some regions only had one program or the other, while some regions had the two programs. Overall, this creates 5 sub-populations, based on unemployment duration, benefit eligibility and location. Only the newly unemployed with sufficient benefit entitlement in areas providing the two programs could be assigned to the two competing treatments (figure 11). They thus play a key role in the comparison between the private and the public programs.

By policy choice, participation to the two programs is voluntary. Correspondingly, the experimental design individually randomized whether one or the other of the two programs was offered to a given job-seeker. More specifically, within each of the 5 subpopulations defined above, randomization was used to create two or three experimental

\footnotetext{
${ }^{10}$ The survey makes a distinction between training programs offered and turned down vs. accepted, and the difference remains for accepted trainings.

${ }^{11}$ The evaluation was conducted by Behaghel, Crépon, Guitard, and Gurgand. The final report (in French) is in Behaghel, Crépon and Gurgand, 2009.
} 
groups: the control group, assigned to the usual track (without intensive counseling), and one or two treatment groups (assigned to the public or the private counseling programs). The randomization took place during the first interview at the local ANPE branch (that is, at registration as unemployed). Once the caseworker had assessed the job-seeker's eligibility, he ran an application on an Extranet to randomly assign him to treatment 1 (public program), treatment 2 (private program) or to the control group (usual track). The probabilities of assignment to each group varied locally and across the different subpopulations so as to maximize the statistical power of the evaluation while complying with the quantitative objectives of each program (each local area had targets in terms of recipients of the two programs). This often implied very high probabilities of assignment to treatment 2 (the private program, up to 85\%) and much lower probabilities of assignment to treatment 1 (the public program, down to 6\%) and to control (down to 9\%).

Upon randomization, the job-seeker was told by the employment service agent which track he was offered. The job-seeker was free to refuse the more intensive tracks. Depending on the assignment and on his early decision during the first interview, he was afterwards contacted either by ANPE services for the usual track, or by a dedicated caseworker from the ANPE-provided intensive program, or by one of the private firms mandated by Unedic. Job-seekers of the two treatment groups effectively entered the program they were assigned to by signing a specific agreement; if they refused to sign, did not show up, or were eventually found not to meet the criteria of the intensive program, they went back to the usual track. Thus, a significant share of each treatment group (about $60 \%$ on average) did not actually enter the program they were assigned to. Following the usual terminology, they are non-compliers. The high rates of non compliance were expected and had been taken into account in the statistical power calculations; along with the unbalanced assignment probabilities, they are a factor limiting the precision of the evaluation. This appears as a price to pay for this large-scale, realistic setting; it is fortunately counteracted by the large samples.

The random assignment took place over 15 months, from January 2007 to March 2008. It took place in 393 local public employment branches, in 16 of the 22 French administrative regions. 67 branches only assigned job-seekers to the public program or the usual track, 91 assigned them only to the private program or the usual track, and the remaining 235 ones had the three possibilities. Overall, 219,033 job-seekers enter the evaluation sample.

The first three columns of table 2 provide evidence that the randomization led to comparable experimental groups. They display sample means for a variety of covariates 
in control (1st column) and treatment groups (2nd column). Differences are small, and rarely significant (column 3), as expected when the different groups are randomly drawn from the same population 12

\subsection{Data}

The primary source of information is the administrative record held by ANPE. It provides basic sociodemographic information on job-seekers and allows to compute the (censored) duration of all registered unemployment spells in the experimental sample. However, as is well known and well illustrated by Card et al. (2007), the end of a registered spell may be due to quite different events. In our data, it is in some cases clear whether the job-seeker has found a job or decided to exit the labor force (for about $50 \%$ of ending spells, the jobseeker returned a form stating his motives or the information was coded directly by the employment services during an interview or a phone contact); but in about $50 \%$ of cases, there is no way to know from the administrative records whether the job-seeker had found a job or not. From this single source of information, we would not be able to attribute exit from the registers to job placement rather than to a discouraged job-seeker effect. As part of the experimental design, a very short phone survey was therefore mandated to an independent survey company, on a subsample of workers whose destination at the exit from unemployment was unknown from the administrative source. The questionnaire was extremely focused so as to actually mimic the form that other job-seekers had filled out upon exiting registered unemployment. It had a maximum of 4 questions. We are using the first one: "Question 1. During the month of ..., you stopped being registered at ANPE. What was the reason?" The sampling probabilities for this survey were optimized to partly correct for the imbalance between treatment and control groups. Moreover, to avoid recall error, the survey was implemented monthly on those who had recently left the unemployment registers, during 12 months after the initial assignment. Thus combined, the administrative records of registered unemployment spells and the short phone survey allow us to measure transitions from registered unemployment to employment at various horizons 13

Sample attrition is quite limited: transitions to employment at the six-month horizon are observed for about $90 \%$ of the sample when job-seekers are eligible for benefits or in the

\footnotetext{
${ }^{12}$ The next two columns are analyzed below.

${ }^{13}$ In parallel, the Ministry of Labor decided to follow an alternative collection strategy by mandating a survey on a sample of about 9,000 job-seekers, including those still registered as unemployed. The survey entails more than 100 questions, providing detailed information on the employment status and search strategy of each worker. However, it is plagued with a low response rate $(50 \%)$ and suffers from large sample selectivity biases (Behaghel et al., 2009). We do not use this survey here.
} 
stock, and for about $80 \%$ of the sample for job-seekers in the inflow who are not eligible for benefits. Within these sub-populations, attrition rates do not significantly differ between control and treatement groups. ${ }^{14}$ Given the low and balanced attrition rates, we treat non response as random (within strata defined by sub-population $\times$ assignment).

Table 3 displays descriptive statistics on the main outcome variables used throughout the paper. Exit rates to employment correspond to the probability that a job-seeker has left unemployment to take a job within 3 months (resp. 6, 9 and 12 months) of randomization. This outcome is thus cumulative and it is analog to (the complement of) a survival function. Depending on the group we consider, exit rates increase form 10$20 \%$ within three months to about 30-40\% within twelve months. Overall, this confirms that the population targeted by the two programs has a high probability of long-term unemployment. The other variables are commented along with the results.

\subsection{Program participation}

As noted above, program participation is voluntary, so that job-seekers assigned to one of the more intensive programs are more likely to enter that program, but are far from systematically doing so. As a consequence, program recipients are a selected sample from the initial population. Technically, this "encouragement design" still allows to estimate the causal impact of the programs on the "compliers". However, it is important to characterize these compliers in order to interpret the effects better.

Table 4 displays take-up rates by initial assignment, in the different sub-populations. Less than half of the job-seekers assigned to an intensive program actually entered it. The reasons for that are diverse, and hard to document. Some job-seekers are eventually found not to be eligible (in particular, eligibility to unemployment benefits is sometimes not well assessed during the first meeting at which randomization takes place). Others may not want to participate, by themselves or because they are discouraged by caseworkers in the programs. Last, administrative failures resulted in some job-seekers not being told which track they were offered, and private companies or ANPE teams in charge of the public program were not always given the adequate lists of job-seekers they had to contact. Overall, non compliance results from a mix of self-selection, selection by the caseworkers (and possibly creaming), and random misallocation. Though our sense from monitoring the experiment is that all these occurred, we cannot directly document it. What can be documented from table 4 is that take-up rates were higher in the private program. Also,

\footnotetext{
${ }^{14}$ Missing observations are due to the combination of two elements: the job-seeker stopped filling out the monthly form stating her employment status without giving a reason (and contacts with the caseworker have ceased), and the job-seeker has not responded to the phone survey.
} 
lower take-up rates for job-seekers who were not eligible for benefits and for long-term job-seekers are consistent with the perception that these job-seekers are less close to the employment services (higher proportion of discouraged job-seekers, and job-seekers who do not depend on the public employment services for unemployment benefits).

It is noteworthy that a few job-seekers assigned to the control (the standard track) entered one of the two intensive programs. This occurred quite rarely (less than $3 \%$ in the worst case, for the private program). The experimental design had in principle excluded the possibility to offer the intensive programs to job-seekers assigned to the standard track. From monitoring the experiment, it seems that the pressure to send job-seekers to private companies induced local PES managers to create parallel lists of job-seekers, independently from the randomization, in order to increase the inflow. These job-seekers were contacted by the private companies and possibly enrolled into the private program, even though some of them were assigned to the public program or to the control. The appendix shows under which conditions the two-stage least squares (2SLS) estimator can still be interpreted as the estimate of the average treatment effect on compliers for each program (LATEs); these conditions seem plausible here.

Given low participation rates, a question of interest is whether the program recipients strongly differ from the original population. Columns 4 and 5 of table 2 display differences in terms of observable characteristics. Program recipients are slightly more educated and more frequently belong to the 30-49 age group. On such other dimensions as citizenship, marital status, number of children, small differences exist, but they go in various directions across sub-populations. Overall, the differences are small even though they are statistically significant due to the large sample size. Table 5 analyzes program participation more directly, using the same variable as table 2 but in a linear probability model, with participation to the programs as the dependent variable. Columns 1-4 confirm the one-to-one mean comparisons of table 2. An interesting question is whether selection into intensive counseling differs between the private and the public program. To address this question, the sample in columns 5 and 6 is restricted to the inflow with unemployment benefits, in areas where the two programs were implemented: job-seekers assigned to the two programs are thus statistically identical. Column 5 shows a large, statistically significant difference in participation, from $32.1 \%$ in the public program to $43.8 \%$ in the private one. Column 6 checks whether the increase in participation is the same across different subgroups (bottom part of the table, interacting assignment to the private program with the different covariates). Two interaction terms are statistically significant, meaning that participation to the private program was particularly high for older job-seekers (a 5.3 percentage point additional increase in participation rate) and for workers who had lost their 
job in a mass layoff (a 4.6 percentage point additional increase). There is thus evidence that the private program attracted or retained a larger fraction of the assigned job-seekers, and some evidence that the populations of recipients ended up being somewhat different, with compliers in the private program having less favorable characteristics in terms of job finding. Section 5 analyzes the corresponding selection issues further.

\section{Impact of private and public counseling programs}

In this section, we present instrumental variable estimates of the impact of the two programs (public and private), on various populations. Specifically, we estimate

$$
Y=a+c_{1}(T=1)+c_{2}(T=2)+u
$$

by 2SLS using random assignment to the public and private programs (respectively, $(Z=$ $1)$ and $(Z=2))$ as instruments for treatment by these programs (denoted by $(T=1)$ and $(T=2)) 15$

Equation 1 is estimated separately for recently registered unemployed ("inflow") and for individuals that have been unemployed at least 3 months at the time of randomization ("stock"). In the inflow, we also distinguish unemployed with and without entitlement to unemployment benefit (UB). To account for the fact that assignment probabilities varied across periods and areas, observations are weighted by the inverse of the assignment probability. Therefore, estimates can be interpreted as LATE on the compliers of the initial population. 16

\subsection{Impact on exit to employment}

In this subsection, we consider the impact of the two programs on exit from unemployment to employment. The outcome in Table 6 is whether the person has left unemployment lists to take a job within 3 months (resp. 6, 9 and 12 months) of randomization. The first implication of this table is that intensive counseling does increase transitions to employment: concentrating resources on unemployed individuals to help them search is

\footnotetext{
${ }^{15}$ Given voluntary participation to the program and the resulting low take-up rates, we focus on LATEs rather than on intention-to-treat (ITT) effects. Indeed, ITT effects are harder to interpret: we postpone their discussion to section 5 on the basis of a simple theoretical model.

${ }^{16}$ In the presence of heterogeneous treatment effects, this is arguably better than using area $\times$ period fixed effects. One can indeed show that the fixed effect estimator artificially gives more weights to areas/periods where assignment probabilities to the control and the treatment groups are close to each other.
} 
effective. This is in line with most empirical research. Orders of magnitude are fairly high. For instance, the baseline exit rate in the control group is $27 \%$ after 6 months in the inflow with UB: this is to be compared with an impact of 4.2 points with the private program and 9.1 points with the public program. Accordingly, exit rate is $30 \%$ in the inflow with no UB, to be compared with an impact of 7.6 points; in the stock, the baseline exit rate is only $22 \%$ and the impact is 3.6 points..$^{17}$ The impacts tend to increase somewhat after the first months of intervention, especially with the private program. Inversely, although the horizon is not sufficient for a strong statement, it seems that the impact tends to stabilize by 12 months.

The second main fact is that impacts are stronger for the public program as compared to the private one. This cannot be judged precisely based on Table6, because all areas are pooled. As the two programs are not delivered in the same regions, the differences could result in part from differences in local characteristics of the market or of populations. In order to make the comparison meaningful, Table 7 presents the impact on inflow with $\mathrm{UB}$, by areas. In the first two columns, the sample is restricted to unemployment agencies where both programs were offered: whether an individual from such an area was assigned to one program or the other is random. The left column is the impact under the private program and the right column the impact under the public program. The last two columns are program impacts in places were only one program was in place.

In areas where the two programs were in place, we can see very strong differences: the public program's impact is 11 points after 3 months, whereas the private program's impact is negligible and non-significant at this early horizon. After 6 months, the private program catches up, but the public program's impact remains twice as large until after 9 months. The difference gets smaller only after one year. It is extremely clear that the impact of the public program is immediate and the differences in survival rates are maintained afterwards. In contrast, the private program is inefficient at the beginning of the counseling period: its impact comes later; it then remains stable over time and keeps being somewhat smaller than the public program. Another striking feature of Table 7, is that impacts are weaker in areas where each program stands alone. A possible interpretation is that the two programs are more effective in areas where they are competing (a stimulation effect). Notice however that effects may also vary by areas for many other reasons: differences in the local labor demand, in the pool of job-seekers, etc.

\footnotetext{
${ }^{17}$ Note that counterfactual exit rates, i.e. exit rates that program recipients would have in the absence of treatment are not exactly equal to exit rates in the control group. Indeed, we estimate local average treatment effects on compliers; compliers differ from one program to another and may have different counterfactual exit rates. The consequences are discussed in section 5 and table 14 . However, this does not modify the general picture, so that we simply use exit rates in the control group as a reference throughout this section.
} 
Tables 8 and 9 show that the efficiency of counseling is not just the result of an artificial effort to send people on very short term jobs. We do not measure directly the duration of jobs, but we know how long it takes for people to register as unemployed again. In tables 8 and 9, we therefore distinguish two kinds of exits from unemployment towards a job: those that last less than 6 months until a new unemployment spell starts, and those that last more than 6 months. We show the impact of treatment on the probability of occurrence of each of those exits, 3 months and 6 months after treatment start ${ }^{18}$ In Table 8 , all types of populations are presented, all areas altogether. We can see that the private program does not increase the occurrence of short exits: all of the impact we found previously corresponds to long lasting exits. In contrast, the public program increases all types of exits, even though its impact on long lasting exits is stronger than on short exits. This is particularly true for the inflow with UB, but remains valid for the other populations. Estimates are imprecise for the stock, because we loose statistical power (and the global estimate was already small at the 6 month horizon), but the same feature applies. To fix ideas, exit rate for more than 6 months are about $20 \%$ after 6 months unemployed in the inflow with UB control group: this rate is increased by 4.8 points by the private program and 6.4 points by the public program.

The first four columns of Table 9 compare the two programs on similar areas (as in Table 7). It shows that the public program is more efficient for two reasons. First, it sends people into jobs associated with short term exits (although this is imprecisely estimated on subsamples), which the private program does not do at all. Second, it is more efficient than the private program at sending out people for long periods of time.

Unédic's logic - save on unemployment benefits - explains why the private program was limited to job-seekers entitled with benefits for a year or more. Another frequent argument is the presumed trade-off between efficiency and equity: job-seekers with more favorable labor market prospects would also take more advantage of job-search assistance services. The above results perhaps provide some evidence in favor of that view: job-seekers in the stock have lower job finding rates on their own, and the private program's impact is lower for them too. Table 10 explores the correlation between own job finding rates and program impacts further, by distinguishing men and women, younger and older job-seekers, and the different educational levels. We focus on exit to employment within 6 months after randomization. The first rows (main effects) show considerable heterogeneity in terms of job-finding rates. College-educated younger men exit faster toward employment. By

\footnotetext{
${ }^{18}$ Given our one year window of observation, we could not observe those types of exits at longer horizons.
} 
comparison, there is little evidence of program impact heterogeneity 19 Younger jobseekers benefit more from the private program in areas where the two programs are present, but not in areas where the private program is alone. Concerning the public program, the only evidence of program heterogeneity is the fact that women in the stock benefit less, which might indicate a weaker labor supply. Overall, we do not find much evidence of program effect heterogeneity; in that sense, there is no evidence of an efficiency/equity trade-off. This is in line with Heckman et al. (2002) reporting little the evidence of (training) program effect heterogeneity, compared to the ex ante heterogeneity of trainees' labor market prospects.

\subsection{Alternative outcomes}

As detailed in section 2, the private program sets explicit criteria of success to private providers (placing the job-seeker in an eligible job within 6 months, for at least 6 months, where eligible jobs must have at least 110 hours per month) that may differ from the (less explicit) goals of the public program. It is therefore useful to compare the impact of the two programs over different criteria. Table 11 compares the two programs on different outcomes in areas where the two programs are simultaneously operating, so that they are not driven by differences in labor market conditions or in initial populations. As shown already, the public program is more effective in terms of exit to employment. Moreover, the coefficient for the private program is quite stable, implying that all of the impact is targeted to "find and keep eligible job" that corresponds to the objective set to private companies. In particular, all of the private provider impact on the larger outcome "exit to employment" is due to placement on the targeted outcome. In contrast, the public program does not only improve placement in terms of the latter outcome, but performs equally well across all types of measures and therefore has a broader placement impact. Even for the outcome for which private providers put all of their effort, the public provider is still $50 \%$ more efficient (although the difference is no longer significant).

\subsection{Elements of financial cost and benefit}

When contracting with private firms, the unemployment insurance fund explicitly assumed that the cost would be covered by increased access to employment, thus decreased unemployment benefit payments. A necessary condition is that treatment reduces the number of days under UB payment. We do not have access to this data, but it can be

\footnotetext{
${ }^{19}$ Note that estimates are less precise, which might partly explain why interaction terms are rarely significant. Overall however, point estimates tend to be lower than for the main effects too.
} 
approximated. As mentioned earlier, the rules set by the unemployment insurance fund is that eligible UB beneficiaries are individuals with at least 365 days of payment eligibility at the time of randomization. Therefore, we can simply count the number of days those persons spent unemployed (even over different spells) during a year, which is directly related to their UB payment.

The fist line of Table 12 presents this result. In spite of the fact that the private intervention does increase exit from unemployment towards employment, it does not decrease the total number of days unemployed. In contrast, the public program does decrease unemployment by 17 to 19 days, which represents a $6 \%$ to $8 \%$ reduction 20

In fact, the French UB system allows people who work less than 110 hour per month to keep some share of their unemployment benefit and remain enlisted as unemployed during the corresponding month. Therefore, some of the days that we count as unemployed are in fact days during which individuals held such occasional jobs and days for which only part of the daily UB was paid. Our data report the monthly hours spent on this job status. From this, we can (approximately) compute a more accurate estimate of the reduction in the number of days receiving UB. This is presented in the second line of Table 12, and results do not change qualitatively.

To understand those results, one must remember that the number of days unemployed over the year has two components: the duration of the unemployment spell, whatever the nature of exit, and the resulting duration out of unemployment. We have some pieces of this. We saw that exit to a job is accelerated by the programs, although less so by the private program, and that this exit tends to last longer. This does not explain why the private program does not reduce the overall presence in unemployment. We thus need to take a look at other types of exits. Table 13 shows that the public program does not affect exits towards other destinations than employment. In contrast, the unemployed counseled by the private firms tend to exit less often towards other destinations. This negative effect is strong, in fact even stronger than the positive employment effect.

More detailed analysis shows that most of this phenomenon is explained by the fact that the unemployed sent to the private providers are much less often excluded from unemployment benefit for failure to fulfill his/her obligations ("radiation"). In contrast, people under the public program are no more and no less excluded. Private providers are not explicitly in charge of monitoring: they only have a counseling role. But the unemployed sent to them are, by contract, no longer monitored by the public service. As a result, they tend to remain longer on unemployment lists. This effect compensates the

\footnotetext{
${ }^{20}$ Over a year, this population in the control group spends between 246 and 263 days in unemployment, depending on the type of zone.
} 
increase in exit to employment, up to the point that the private treatment is neutral to the number of days spent unemployed; thus also to the unemployment benefit payment.

It is thus ironical that private providers, enrolled by the unemployment insurance fund, likely did not generate reduction in unemployment benefit, whereas the rival public program did so. Naturally, this is by no means a normative judgment, because we can make no claim on the welfare impact of exclusion from UB lists, one direction or another. But it has financial implications. Unfortunately, we did not have access to existing data on the amounts of unemployment benefits and costs of the program, so that we can only provide tentative orders of magnitude. Our own computations yield a payment around 1,500 euros per treated job-seeker; this does not account for management costs on Unédic's side. Because we expect no financial benefit, this is also the net cost for an average additional $6 \%$ chances to enter a job.

In conclusion, as it was experimented in 2007, intensive counseling provided by private firms proved to be less efficient, certainly not self-financed, and probably much more costly than similar intervention by the public service. A second finding is that private providers seemed to respond closely to the detailed incentives of their contract. We now turn to the one hypothesis that builds upon these two findings: did the private providers perform less well than the public program because it was in their best interest, given the incentives they were facing?

\section{$5 \quad$ Why are private providers lagging behind?}

In this section, we address a prominent issue in the debate on outsourcing public services like job-search assistance: do the financial incentives set to private providers lead to better outcomes? We argue that the inability of the principal (the unemployment insurance fund) to provide private firms with the incentive to act optimally is a plausible explanation for their surprisingly low performance, and we provide a set of stylized facts in support of this interpretation. We also discuss alternative explanations.

The argument can be summarized as follows. We assume that the two programs have access to the same technology and to identical pools of applicants (we discuss these assumptions further in section 5.4). In that context, the lower performance of the private program must be due to the fact that private providers apply the counseling technology less intensively and/or apply it on job-seekers on whom it is less effective. This can occur in at least two cases. In a first case, private providers can be induced by their contract - specifically, the premium $P_{1}$ that they receive each time a job-seeker finds a job - to 
selectively enroll job-seekers with better job market prospects and discourage those with lower own job finding rates, even though the latter may be the job-seekers for whom counseling is most effective. In a second case, private providers can be induced by the second feature of their contract - the large unconditional upfront payment $P_{0}$ that they receive each time a job-seeker signs in - to make all their effort to persuade as many job-seekers as possible to enroll. Either case - discouraging job-seekers for whom the program is effective, or attracting job-seekers for whom it is ineffective - leads to lower program impact, by distorting the pool of enrollees toward those with low treatment effects. We develop a simple agency model in which the contract set by the principal (the UB fund) can lead providers to behave according to these two cases, depending on the size of the unconditional and conditional payments, $\left(P_{0}, P_{1}\right)$. We show evidence that private providers actually behaved according to the second case, maximizing enrollment into the program rather than cream-skimming, and probably providing a bare minimum of service to some job-seekers ("parking"). The key reason for that is the very high upfront payment $P_{0}$ that largely pays for the marginal cost of enrolling any job-seeker. By contrast, the public program, as it is managed in house in the PES, has to internalize the scarcity of caseworkers, and has no incentive to maximize enrollment. This can explain why enrollees in the public program have on average stronger treatment effects than in the private one.

For some part, the evidence we bring is of course specific to the context of the job-search experiment that took place in France in 2007-2008. However, the basic arguments and the theoretical mechanisms at play are more general, especially given that the payment structure - a fixed upfront payment, plus a conditional payment if placement occurs within a given period - has become common in European countries that outsource the placement of job-seekers ${ }^{21}$ Moreover, upfront payments as large as one third of the maximum total payment are not exceptionally large. Our simple model and the perverse effects of a large upfront payment may therefore shade light on a general problem in the way job search assistance has been frequently outsourced.

\subsection{An agency model with heterogeneous job-seekers}

We start by formalizing the agency problem faced when outsourcing job search assistance in a simple model 22

\footnotetext{
${ }^{21}$ Examples include Germany, the Netherlands, Sweden, etc. See Winterhagen et al. (2006), Struyven and Steurs (2002), and Bennemarker et al. (2009).

${ }^{22}$ The problem of striking a balance between "cream-skimming" and "parking" when outsourcing the placement of job-seekers is clearly stated in Struyven (2004), but we are not aware of any formal analysis. Heckman et al. (2002) provide a very clear discussion of cream skimming in a similar setting, but with a different incentive scheme (a performance standard) applied to public training centers. The problem is
} 
Consider a static (one period) agency model. The goal of the principal - the unemployment benefit provider, denoted by $\mathrm{U}$ - is to minimize its benefit spending $B$ on a given pool of heterogeneous job-seekers entering unemployment. $B$ is paid unless the job-seeker finds a job by herself, which occurs with probability $\lambda$.

A counseling technology is available that allows to increase job finding rates from $\lambda$ to $\lambda+\delta$, at cost $c$ per job-seeker. It would therefore be privately optimal for $\mathrm{U}$ to provide counseling to all job-seekers such that $\delta B \geq c$. However, $\mathrm{U}$ decides to outsource the provision of counseling to private providers, under a two-tier payment structure: $\left(P_{0}\right.$, $\left.P_{1}\right)$. Job-seekers are heterogeneous in $(\lambda, \delta)$, i.e. in their propensity to find a job on their own $(\lambda)$ and in the impact counseling has on them $(\delta){ }_{23}^{23}$ The type of a job-seeker is not observed by the principal (U); it is however observed by the agent (the private provider) at the first meeting with the job-seeker. The agent thus has the possibility to screen jobseekers; he can also decide to accept the job-seeker but provide her with minimal service: in that case, the cost of enrolling the job-seeker is purely administrative (and denoted by $c_{a}$ with $c_{a}<c$ ), but enrollment is ineffective: we assume that the job finding rate then stays at $\lambda$.

From the principal point of view, the first best solution is to enroll and treat all jobseekers with $\delta B \geq c$ and no to enroll job-seekers with $\delta B<c$. However, cream-skimming occurs when enrollment is an increasing function of $\lambda$ for some $\delta$ : people with little own labor market prospects are excluded from the treatment, even though their value of $\delta$ would justify treatment. Parking occurs when the agent enrolls, but does not actually treat, some job-seekers: given $\lambda$, this is likely to occur for job-seekers with small $\delta$. Notice that there is a double problem with parking: some people with low gains from the program $(\delta<c / B)$ can be enrolled and parked although they should be neither enrolled nor treated from the principal point of view; and some job-seekers with intermediate gains from the program can be enrolled and parked although they should be enrolled and treated from the principal's point of view.

Consider the private provider's incentives. Its efforts can be of two types. The first

\footnotetext{
also reminiscent of standard problems in health economics on optimal reimbursement schemes to health care providers - see in particular McClellan (2011), Newhouse (1996), and Ma (1994). However, the main comparison in that context is between prospective payments (fixed, possibly risk-adjusted payment per patient) and fee-for-service reimbursement. For the placement of job-seekers, fee-for-service payments are rarely considered, but payments are indexed on an individual performance measure (finding a job or not). Performance measures are less obvious in the health care context and still play a limited role (McClellan, 2011). As a result, models from health economics do not directly apply in our setting. However, the variety of payment schemes considered in the health economics literature underscores the fact that the structure of payment chosen by Unédic is only one out of many possibilities. Our discussion holds only within that particular type of contracts.

${ }^{23}$ For the sake of simplicity, $c$ and $B$ are supposed to be identical across job-seekers.
} 
type of effort is to register the job-seeker into the program and park him at cost $c_{a}$ (administrative cost). The gain in this case is simply $\Pi_{0}=P_{0}+\lambda P_{1}-c_{a}$. The second type of effort is to register the job-seeker into the program and provide her with the treatment at costs $c>c_{a}$. The gain in that case is $\Pi_{1}=P_{0}+(\lambda+\delta) P_{1}-c$. The operator's decision is quite simple. If $\Pi_{0} \leq 0$ and $\Pi_{1} \leq 0$, the job-seeker is not enrolled. If $\Pi_{0}>0$ but $\Pi_{1} \leq \Pi_{0}$, the job-seeker is enrolled and parked. If $\Pi_{1}>0$ but $\Pi_{1}>\Pi_{0}$, the job-seeker is enrolled and treated. Those conditions define the types $(\lambda, \delta)$ of job-seekers that are either not enrolled, parked or treated.

Figures 2 and 3 , drawn in the $(\delta, \lambda)$ space, make clear how choices $P_{0}$ and $P_{1}$ shape enrollment and treatment. Two cases are considered one with $P_{0}$ larger and one with $P_{0}$ lower than administrative costs. In figure 2, $P_{0}>c_{a}$ thus $\Pi_{0}$ is always positive. Then, everybody is enrolled because it is always profitable for the firm to have individuals in its list. However they do not all receive treatment and some of them are parked (area PA1). Only job-seekers with $\delta>\left(c-c_{a) /} P_{1}\right.$ are treated (area TR1). In figure $3, P_{0} \leq c_{a}$. Now, cream-skimming appears because job-seekers with low $\lambda\left(\lambda \leq\left(c_{a}-P_{0}\right) / P_{1}\right)$ are not enrolled, except if they have a large value of $\delta$ (area CR2). Job-seekers with higher $\lambda$ but low $\delta$ are worth enrolling but they are parked (area PA2). Finally, job-seekers with high $\delta$ are enrolled and treated.

Obviously, this two-tier payment structure is sub-optimal. In both figures, the horizontal dashed line at $c / B$ identifies the populations that should (above) or should not be treted (below) from the principal point of view. Parked job-seekers are thus of two types: those that should not enter the program from the principal point of view because their value of $\delta$ is to low $(\delta<c / B)$ and those that should have received treatment $(\delta \geq c / B)$, but were not treated by the provider because $P_{1}$ was too low. In figure 2, if $P_{1}$ was set adequately, all individuals that should receive treatment would indeed receive it, but the remaining job-seekers would still be uselessly enrolled. In figure 3, some job-seekers that should be treated would remain un-enrolled. Regarding, $P_{0}$, as it decreases, the share of individuals excluded from the treatment increases. More job-seekers that should not enter the program become excluded from the program but it is at the expense of excluding also more job-seekers that should enter the program. How first-best could be achieved with other forms of contracts is beyond this discussion. 


\subsection{Do private and public providers cream-skim and park job- seekers?}

This model predicts that, as the upfront payment $P_{0}$ increases, the firms have an incentive to enroll more and more job-seekers, to the point that some of them are parked. As long as $P_{0}$ is larger than administrative $\operatorname{costs} c_{a}$, general enrollment is optimal to the firm. We discuss here the orders of magnitude and show that it is likely to be the case for the private providers. We also discuss the public provider behavior.

Price $P_{0}$ in private providers contracts was set around 1,000 euros, which seems a large figure. Unofficial information on the cost of actual treatment (not parking) in the public program indicates a maximum of 600 euros per individual. It is therefore unlikely that 1,000 is below the administrative cost of enrollment with minimal effort. To fix ideas, the contract with the UB fund states that there should be no less than one caseworker per 40 job-seekers, with follow-up lasting 6 months at most. This sets a minimum labor cost. Correspondingly, minimum payment is thus 80 times $P_{0}+\lambda P_{1}$ per caseworker. Given that $\lambda$ is to the order of $30 \%$ after 6 months, this alone would pay an annual wage above 128,000 euros ${ }^{24}$ This is to be compared to the minimum wage (25,200 euros), the average wage in the service sector (40,000 euros) and average manager wage in the service sector (76,000 euros). Even if this is only a share of administrative costs, this price structure is therefore extremely likely to encourage private providers to enroll as many job-seekers as possible, whatever their types, even if to treat only some of them efficiently.

Divay (2009) independently conducted interviews with caseworkers and managers in two private providers' branches. She reports that although caseworkers do not talk about parking, they describe a highly standardized procedure that clearly saves on the private providers' main cost: the caseworkers' time. Indeed, each job-seeker meets with the caseworker weekly, for a well-defined thirty-minute sequence that one caseworker describes in the following terms: "Offer coffee, review last week's objectives, suggest actions, perhaps make a call, set new objectives for the coming week, set up a new appointment, and accompany the person to the door. This is the procedure!" (Divay, 2009, p. 44).

Therefore, we expect that private providers behavior is characterized by the case presented in figure 2 with $P_{0}>c_{a}$ : as many job-seekers as possible are enrolled and a share of them (depending on $P_{1}$ ) are parked. This can explain a lower impact relative to the public program if the behavior of caseworkers in the public program is different. A difficulty here is that there is no specific contract defining the incentives in the public program;

\footnotetext{
${ }^{24}$ For a 6 month period, a caseworker has a portfolio of 40 job-seekers generating 40,000 euros, in addition $30 \%$ of them, i.e. 12 , get a job within the 6 month period generating 24,000 euros. For a six month period the parking strategy yields at least 64,000 euros, which makes 128,000 for a year.
} 
moreover, other elements (non financial incentives, altruistic behavior,...) may play an important role. However, caseworkers and managers in the public program share the general objectives of the PES. These objectives are set by the government. As of 2007-2008, the PES had to (i) act as the main intermediary between firms and job-seekers; (ii) orient job-seekers to programs (e.g. training) funded by the State, the UB fund, and local authorities; (iii) manage the unemployment registers; (iv) counsel job-seekers (Convention tripartite, 2006). The PES chooses quantitative objectives based on these general goals; they are of two broad types: number of exits to job (the job-seeker's perspective) and number of satisfied job offers (the firms' perspective). These objectives are passed on to managers and caseworkers, even though probably in a looser way than for the private providers. But the main difference is probably the fact that the public program had no incentive to maximize the enrollment of job-seekers, for at least two reasons: its main criterion of success is a placement rate (implying that job-seekers with lower labor market prospects and/or lower program impacts are to be avoided), and the human resources available to the program are limited. Indeed, the public program's caseworkers come from the standard track, where they are a scarce resource. This is in sharp contrast with the private program, for which each additional job-seeker implies new resources $\left(P_{0}\right)$.

Overall, a highly stylized representation of the public program's implicit "payoff" could

be written as $\tilde{P}_{0}+\tilde{P}_{1}(\lambda+\delta)$, just like for the private program, but with $\tilde{P}_{0}<<P_{0}\left(\tilde{P}_{0}\right.$ close to 0 , and even possibly negative). The behavior implied by the previous model shows that in this case caseworkers tend to cream-skim. Some job-seekers with low $\lambda$ that should receive the treatment are excluded from the program, and figure 2 could be a fair approximation to the public program, in view of contrasting it with the private one.

This representation has testable implications: we now turn to them and show that this model can explain the different performances of the two programs.

\subsection{Empirical facts that the model can explain}

Take-up. A first implication of the model is that private providers should maximize enrollment into their program unconditionally. Indeed, as already mentioned, program participation is substantially higher in the private program as compared to the public program: $43 \%$ instead of $32 \%$ in similar areas (see table 5), i.e. a $30 \%$ difference.

However, those take-up figures suggest that a significant share of the low participation must be explained by job-seekers reluctance to enter the counseling programs. As detailed in section 5.4 below, based on survey data, many of the refusing job-seekers expect to find 
better jobs if they search on their own (or they report that they already have a job in view). This points to a behavior where individuals with high $\lambda$ are reluctant to enter, and expected value of jobs is lower in the program. We can represent this very simply by assuming that job-seekers who enter the program are such that

$$
(\lambda+\delta) V^{T}-\Psi>\lambda V^{N T},
$$

where $V^{T}$ is the perceived value of a job found within the program and $V^{N T}$ that of a job found on one's own, with $V^{T}<V^{N T}$; and $\Psi$ is a psychic cost of program participation. Under those assumptions, a share of the population will not enter the program: this is represented by area below the increasing line in figures 4 and 5 , in a case where job-seeker self-selection is such that agency problems remain 25 In the end, most of the low take-up may be explained by individual behavior, but the fact that it is relatively higher in the private program is compatible with the fact that a high $P_{0}$ induces private firms to enroll as many people as possible. This behavior is again illustrated by Divay (2009) who reports that caseworkers are making all possible effort to persuade all job-seekers to enroll: they play down the constraints of the program, suggest that refusals could be misinterpreted by the UB administration, etc. They explain that their management's main concern is about unfilled slots.

Cream-skimming. The second implication of the model is that private providers should not cream-skim, whereas the public program may. Looking at figures 4 and 5 , it is apparent that self-selection should bias enrollment towards individuals who have lower values of $\lambda$ and this is indeed what the survey evidence already discussed seems to suggest. This should be mostly apparent for the private program, because no cream-skimming is expected to occur.

Thanks to the randomization design, we can compute the counterfactual outcomes of the compliers to the two programs if they had not been treated, $E\left[y_{0} \mid C o m p_{p r}\right]$ and $E\left[y_{0} \mid C_{\text {omp }}\right]_{2^{26}}^{26}$ This is a measure of $\lambda$ in the model. As shown in details in the statistical Appendix, even though our setting has two treatment groups rather than one, the standard

\footnotetext{
${ }^{25}$ With a very high psychic cost $\Psi$, only high $\delta$ individuals would remain and the agency problem would no longer be apparent - but in this case, participation rates would be similar in both programs and none of the coming empirical facts would be present.

${ }^{26}$ Note that, as there are almost no always takers, "compliers" here are almost the same as program participants.
} 
interpretation of the two-stage least squares (2SLS) estimands holds:

$$
c_{s}=E\left[y_{s}-y_{0} \mid C o m p_{s}\right]
$$

with $s=p r, p u b$, so that $E\left[y_{0} \mid C o m p_{s}\right]$ (for compliers to program $s$ ) is identified as

$$
\begin{aligned}
E\left[y_{0} \mid C_{o m p}\right] & =E\left[y_{s} \mid C o m p_{s}\right]-E\left[y_{s}-y_{0} \mid C_{o m p}\right] \\
& =E\left[y \mid Z=s, C o m p_{s}\right]-c_{s}
\end{aligned}
$$

(where $Z$ is assignment to treatment). Estimates of $c_{p r}$ and $c_{p u b}$ have been presented in the previous section. The empirical counterpart of $E\left[y \mid Z=s, C o m p_{s}\right]$ is directly observed. The resulting counterfactual own job finding rates are presented in table 14 (Panel B) altogether with observed outcomes for compliers (Panel A) and outcomes in the control group (Panel C) for the two outcomes relevant to the private providers. Using the outcome "found and kept eligible job", we can see that the quality (in terms of own finding job rate) of the population treated by private providers is significantly smaller than that of the total population ( $18.4 \%$ chances to get such job within 6 months, as compared to $21.4 \%$ in the control group); the same is observed for the other outcome, although differences are smaller. In contrast, the population that enters the public program is similar to the control group: this is compatible with the fact that self-selection in compensated by some cream-skimming. To sum up, there is no evidence of cream-skimming from private providers: they seem to maximize entry, even at the risk of enrolling job-seekers with low own job finding rates, something that is rational under high $P_{0}$.

LATE. A third stylized fact is that intention to treat parameters (ITT) should be closer between the private and public programs than are local average treatment effects (LATE). With reference to figures 4 and 5 , ITTs are

$$
\begin{aligned}
& \mathrm{ITT}_{p r}=E(\delta \mid \text { Area TR3 }) \operatorname{Pr}(\text { Area TR3 }) \\
& \mathrm{ITT}_{p u}=E(\delta \mid \text { Area TR4 }) \operatorname{Pr}(\text { Area TR4 })
\end{aligned}
$$

and 


$$
\begin{aligned}
\text { LATE }_{p r} & =\frac{E(\delta \mid \text { Area TR3 }) \operatorname{Pr}(\text { Area TR3 })}{\operatorname{Pr}(\text { Area TR3 })+\operatorname{Pr}(\text { Area PA3 })} \\
\text { LATE }_{p u} & =\frac{E(\delta \mid \text { Area TR4 }) \operatorname{Pr}(\text { Area TR4 })}{\operatorname{Pr}(\text { Area TR4 })+\operatorname{Pr}(\text { Area PA4 })}
\end{aligned}
$$

ITTs are reported in table 15. For the outcome "find and keep eligible job within 6 months", coefficients are 0.020 for private providers and 0.022 for the public provider respectively; for the outcome "find eligible job within 6 months", they are 0.15 and 0.20. Relative values of the LATEs are somewhat different (table 11): 0.050 vs. 0.072 and 0.039 vs. 0.063 respectively for the two outcomes. Close ITTs are consistent with a situation where the populations treated by the two programs are not very different in terms of size and composition. The difference in LATEs in turn implies that the enrollment rate is higher in the private program. This is consistent with the model's prediction that the public program does not enroll some job-seekers who would be enrolled but parked in the private program. Put differently, LATEs differ while ITTs are similar because $\operatorname{Pr}($ Area PA3 $)>\operatorname{Pr}($ Area PA4), with the difference between those two areas coming from individuals who are not treated in either case, and thus do not contribute to the ITTs.

In a nutshell, comparing ITTs and LATEs suggests that the difference in LATEs between the two programs comes from the fact that some of the additional job-seekers that are enrolled by the private program are not treated, or inefficiently so. In that sense, this model can explain the differences in LATEs observed initially. It is also compatible with additional empirical facts.

\subsection{Alternative explanations}

Our preferred explanation of the private program's lower performance is thus based on the claim that private providers tried to enroll as many job-seekers as possible, including some for whom job search assistance is ineffective. By contrast, the public program remained concentrated on a lower fraction of job-seekers for whom the technology is effective. We now confront this proposed explanation to other possible stories.

Job-seekers' self-selection. One way to account for differential participation in the two programs is differential self-selection by the job-seekers. It is possible that more job- 
seekers were willing to enter the private program, with the hope of finding services that were not provided within the PES (in the standard track or the intensive public program alike). If these additional job-seekers are mistaken - and actually derive no benefit from the private providers' assistance -, their presence among program recipients will inflate enrollment rates but reduce the average program impact.

The reasons declared by job-seekers for enrolling or not into the programs, as reported in Gratadour (2009) ${ }^{27}$, do not support this unbalanced self-selection story. In particular, enrollees in the private and public programs declare very similar motivations. $84 \%$ of private program enrollees and $83 \%$ of public program enrollees say they wanted to "receive more training and assistance" in their search for a job, $80 \%$ and $83 \%$ (for private and public programs, respectively) say they expected to "receive more job offers fitting [their] profile", $79 \%$ and $84 \%$ wanted to "benefit from a more intense and customized follow-up". If anything, enrollees were expecting slightly less from the private program. Similarly, the most frequently cited reasons for not enrolling are "having already a job in view" (52\% and $55 \%$, for job-seekers who did not enrol when assigned to the private and public programs, respectively) or "expecting to find a job thanks to own network" (54\% and 54\%). In sum, even though these self-reported motivations are only indirect evidence, they do not indicate that job-seekers self-selected differently into the private program.

Learning. The next two other alternative explanations release the assumption that private providers were as efficient technically as the public program. Although private providers were using the same technology as the public program, as already shown, a frequent argument is that private providers were just starting this activity and needed time in order to become fully operational. Another argument is that private providers did not have access to the appropriate pool of job offers, whereas the PES had built relationships with small and medium-size firms where it could place job-seekers. These two explanations are plausible. However, it seems unlikely that they tell the full story; we consider them in turn.

It may have taken some time for the private providers to be operational, recruit and train the counselors, whereas the public service could allocate some of its experienced caseworkers to the intensive scheme. This would imply that the private program was less efficient during the first months of the experiment, and that its impact then caught up that of the public program. In order to check this, we can compute program impacts separately by cohort of entry. Figure 6 traces program impact after 6 months, for the two

\footnotetext{
${ }^{27}$ The data comes from the survey on a subsample of job-seekers already used to describe the programs' content in section 2 .
} 
programs, in areas where they are both present. This is reported on the left-hand scale, where the impact is estimated separately by 2 -month cohorts. This is to be compared with Table 7 where the average impact is estimated at 0.045 and 0.102 for private and public programs respectively. The figure shows that these average estimates hide very strong changes in impact over time. But this certainly does not go in the direction of learning by doing. The two programs had very strong impacts at the beginning, then their impact dropped essentially to zero, and recovered thereafter. The small sample sizes imply that estimates are now imprecise and the effects are significant only at the beginning and the end of the period. However, the likely reason for this switch appears on the right-hand scale, that shows the variation in the number of entrants in the program. This number increased 3 to 4 -fold during the first two months of the experiment. In both programs, efficiency dropped when the number of beneficiaries started to increase. This is compatible with the idea that such programs are efficient mostly thanks to the low unemployed/caseworker ratio, as this ratio did increase suddenly if it took time for the programs to scale up. All in all, Figure 6 is very consistent with the general findings of the paper, but does not deliver evidence that private providers lagged behind because of learning by doing or training issues.

Access to job offers. As noted in section 2, there is evidence that the private program caseworkers provided job-seekers with fewer job offers. However, the reason for that remains an open question: it may be that private providers were less efficient at collecting job offers, or that they invested less in that activity. The first explanation would be rather ironical, as a key argument for introducing private providers in job-search assistance was their better connection to the labor market (compared to a less market-oriented PES). Private providers were indeed experienced players in the labor market: temporary agencies, consultancies specialized in the placement of workers after mass layoffs, or even international firms specialized in job-search assistance programs. Given that experience, it seems that a full explanation needs to tell why they did not invest successfully in job offer collection. Ultimately, this goes back to the incentives question ${ }^{28}$

\footnotetext{
${ }^{28}$ Interestingly, qualitative work at one private provider shows that the internal organization of work devolved limited ressources to job offer collection. No specific staff was devoted to the activity, and caseworkers were supposed to spend only two hours per week on collecting job offers. Moreover, the caseworkers' financial incentives were almost uniquely based on placement results. Interviewed caseworkers argued that developing a portfolio of client firms to place the job-seekers was not worth the effort: they rather targeted new firms on a case by case basis according to each job-seeker's profile and limited capitalization effort was undertaken; after one year, a given caseworker said he had a portfolio of fewer than twenty client firms (Divay, 2009).
} 


\section{Discussion}

The large field experiment we just analyzed yields some basic facts - job search assistance accelerates exit to employment, and public provision is more cost effective in our context. As such, these results may be highly context specific. The evidence on unexpected perverse effects of the private providers' contracts allows to go one step further, by highlighting traps and trade-offs faced when outsourcing such services. There remains however a disturbing question in the analysis: Why would the UB fund design contracts with such large, suboptimal fixed payment $P_{0}$ ?

First, one should not dismiss the idea that outsourcing such services implies a trial and error process. Informal discussions with policy advisors suggest that the discussion on contract structure was actually limited. It is plausible that the UB fund failed to recognize the consequences of the large upfront payment, as it failed to recognize that during the private program, as noted above, neither the PES nor the private providers would monitor the administrative status of job-seekers, thus unduly maintaining benefit payments to some of them. However, a similar structure (with a slightly higher upfront payment, from $30 \%$ to $35 \%$ ) was reconducted for a new wave of contracts involving 320,000 job-seekers in 2010-2011: this suggests that learning on contracts is slow, or that it is not the full explanation 29

A second possibility is that our theoretical model is too simple: admittedly, a more complete agency model could rationalize large fixed payments. In particular, one could release the assumption of risk-neutral private providers. Large fixed payments may then play a role to insure risk-averse private providers, as discussed for instance in Koning and Heinrich (2010), although it is not clear whether this would be the most appropriate mechanism. More generally, our simple model takes the two-tier contract structure as given, and just asks about the optimal share of conditional and fixed payments. This is a very restrictive class of contracts, and it would be very useful to investigate - and experiment with - a broader class of contracts 30

\footnotetext{
${ }^{29}$ The other element of the contract - the winning bid price - retained more attention of policy makers. As noted above, they ranged from 3,000 to 4,000 euros. These amounts are hard to benchmark; in the Netherlands, price of trajectories seem to be of the same order of magnitude; but trajectories could last up to two years, compared to 6 months in France. A better benchmark would be the cost of the comparable public program. However, in the context of this evaluation, the PES stopped its effort to evaluate the unit cost of the public program half way, finally arguing that numbers would not be reliable. While imputing the private program costs in the PES accounting system was undoubtedly difficult, it had also clearly become politically incorrect to compare the costs of the public and private programs at a time where the decision had been taken to expand the private program dramatically.

${ }^{30}$ In particular, contracts could involve a fee $Q$ for the right to deliver the program under the two tier payment $\left(P_{0}, P_{1}\right) . \quad P_{0}$ and $P_{1}$ could be set to align the objectives of the private providers with those of Unédic $\left(P_{0}=c_{a}\right.$ and $\left.P_{1}=B \frac{c-c_{a}}{c}\right)$. Under such a contract, all job-seekers are enrolled into the
} 
However, we believe that the main explanation has to do with the political economy context of the experiment. The UB fund was eager to create an (up to then) inexistent private market for placement. Firms likely to step in this market in France would need to bear a large fixed cost and would not enter unless they had some assurances that the fixed cost would be easily covered. This infant industry argument should have implied, if anything, that the principal would make a lump-sum transfer to the firms, rather than a transfer indexed on the number of enrolled individuals, but this was never considered (and would raise moral hasard issues of its own). Moreover, internal pressures (from firm unions within the UI fund and from the government) and external ones (from other EU countries' example and from the European Commission) converged to promote private providers. The infant industry argument may have been used as a justification for offering attractive contracts to private providers. Imitation was also at play: the chosen contract structure is close to outsourcing contracts used in several other European countries. ${ }^{31}$

\section{Conclusion}

The episode analyzed in this paper offers stimulating evidence: to sum up, in the context under study, counseling is effective (in the sense of accelerating placement), but cost effectiveness of contracting-out is less clear, and contracts to private providers (using a structure that has become common to many OECD countries) seem suboptimal. A similar finding was obtained by Krug and Stephan (2011) based on a field experiment in Germany. Interestingly, even though the outsourcing trend generalized to many countries over the past decade, it is not monotonic: for instance, in the Netherlands, the outsourcing of welfare services was partly reversed in 2007, as the social benefit administration resumed the delivery of welfare to work services for job-seekers with good labor market prospects (Koning and Heinrich, 2010). It is also interesting to note that the US Public Employment Office was created in the US at the turn of 20th century to regulate the job-seeker

program and only job-seekers with $\delta>B / c_{1}$ actually receive the treatment. Unédic can then require a fee $Q=N F_{\delta}(B / c)$ where $N$ is the size of the population eligible for the program. Of course, this would have to be adjusted for the fact that the distribution of $\delta$ may not be known ex ante. Also, note that $c_{a}$ is paid for job-seekers that are not treated, but this may be viewed as a cost which would be incurred anyway if these job-seekers were enrolled in the standard track.

${ }^{31}$ For instance, contract providers in UK "Employment Zones" received a three-tier payment (at enrollment, at job entry and after 13 weeks of retention in a job). Contracts in Germany varied, but often resembled the French ones - e.g. a contract with Ingeus, an early and influential private provider on the French job-seeker placement market, involved a $56 \%$ upfront payment, $10 \%$ on job placement, $17 \%$ after 13 weeks and $17 \%$ after 26 weeks of sustained employment. In the Netherlands, even though fully conditional payments ("no cure, no pay") were introduced progressively in the mid 2000s, the typical "no cure, less pay" contract involved a 10 or $20 \%$ payment on completion of an agreed action plan, a fixed payment of about $40 \%$ six months after commencement and another $40 \%$ or $50 \%$ after placement in a job for two months, with a minimum six month contract. See Finn (2011) for a review. 
placement market which was dominated by for profit employment agencies perpetrating abuse towards vulnerable individuals (Lee, 2009).

Clearly, this does not mean that private providers should not be used for job-search assistance: we find in particular some (admittedly fragile) evidence that competition from private providers may in part explain the performance of the public program. But public authorities, in France at least and in other countries perhaps, are still at the beginning of a learning curve. That point is implicitly acknowledged by a recent review mandated by the European Commission: "The development and management of subcontracting systems is a complex task for policy makers and public officials. There is a sharp and continuous 'learning curve' and it takes time to learn how to steer the system to minimise perverse incentives and to capture the efficiencies and innovation that independent contractors may offer. It may be that the gains from subcontracting emerge over time when, as in Australia, public officials can exclude poorer performers, increase competition and improve the performance management of subcontractors." (Finn, 2011, p. 32). An ideal direction for research would be to design outsourcing contracts that take into account micro evidence on job-seekers', caseworkers' and firms' behavior, and experiment them with robust evaluation methods. 


\section{References}

Ashenfelter, O., A. Ashmore and O. Deschênes (2005), "Do Unemployment Insurance Recipients Actively Seek Work? Evidence from Randomized Trials in four U.S. States", Journal of Econometrics, vol. 125(1-2), pages 53-75.

Assemblée Nationale (2009), Question n86753 by Michel Vauzelle to the Minister of Labor, Employment and Health, http://questions.assemblee-nationale.fr/q13/13-86753QE.htm

Autor D. and S. N. Houseman, 2010. "Do Temporary-Help Jobs Improve Labor Market Outcomes for Low-Skilled Workers? Evidence from "Work First"', American Economic Journal: Applied Economics, vol. 2(3), pages 96-128, July.

Behaghel, L., Crépon, B., and M. Gurgand (2009), "Evaluation d'impact de l'accompagnement renforcé des demandeurs d'emploi par les opérateurs privés de placement et le programme Cap vers l'entreprise", Research report, http://www.povertyactionlab.org/sites/default/files/publications/Rapport\%20Final-\%20CREST-ENSEE.pdf

Behaghel, L., Crépon, B., and M. Gurgand, and T. Le Barbanchon (2009), "Sample Attrition Bias in Randomized Experiments: A Tale of Two Surveys", IZA Discussion Paper 4162.

Bennemarker, H., Grönqvist, E., Öckert, B., (2009), "Effects of Outsourcing Employment Services: Evidence from a Randomized Experiment", Institute for Labour Market Policy Evaluation (IFAU), WP09-23.

Bernhard, S., Wolff, J., (2008), "Contracting out Placement Services in Germany - Is Assignment to Private Providers Effective for Needy Job-seekers?", IAB Discussion Paper $5 / 2008$.

Besley, T., Ghatak, M., (2001), "Government versus Private Ownership of Public Goods", The Quarterly Journal of Economics, vol 116(4), pp.1343-1372.

Blundell, R., Dias, M. C., Meghir, C. and van Reenen, J. (2004), "Evaluating the Employment Impact of a Mandatory Job Search Progra", Journal of the European Economic Association 2, 569-606. 
Capelier, T., Mizrahi, R. (2008), "L'accompagnement renforcé des demandeurs d'emploi. L'évaluation qualitative de la mise en oeuvre des expérimentations", http://www.travail-emploi-sante.gouv.fr/IMG/pdf/2008.07-27.5.pdf

Card, D., R. Chetty, and A. Weber (2007), "The Spike at Benefit Exhaustion: Leaving the Unemployment System or Starting a New Job", American Economic Review Papers and Proceedings, 97(2), 113-118.

Card, D., J. Kluve, and A. Weber (2010), “Active Labour Market Policy Evaluations: A Meta-Analysis", Economic Journal, 120 (November), F452-F477.

Convention tripartite (2006), Signature de la convention Etat-Anpe-Unédic relative à la coordination des actions du Service Public de l'Emploi, http://www.emploi.gouv.fr/chomage/recherche/actualite/DP_Signature_de_la_convention_Etat-Anpe-Unedic__vendredi_5_mai_2006.pdf

Courty, P. and G. Marschke (2004), "An Empirical Investigation of Gaming Responses to Performance Incentives", Journal of Labor Economics 22(1), 23-56.

Divay S. (2009), "Nouveaux opérateurs privés du service public de l'emploi. Les pratiques des conseillers sont-elles novatrices?", Travail et Emploi 119, 37-49.

Dolton, P. and O'Neill, D. (1996), "Unemployment Duration and the Restart Effect: Some Experimental Evidence", Economic Journal, 106, 387-400.

Dolton, P., O'Neill, D., (2002) "The Long-Run Effects of Unemployment Monitoring and Work-Search Programs: Some Experimental Evidence from the U.K.", Journal of Labor Economics, 20(2), pp.381-403.

Duggan M. (2000), "Hospital ownership and public medical spending", Quarterly Journal of Economics, 115, 1343-1373.

EC (1998), "Modernising public employment services", Communication from the European Commission of 13 November 1998, http://europa.eu/legislation_summaries/employment_and_social_policy/job_creation_measures/c10926_en.htm

Finn D. (2011), "Sub-contracting in public employment services. Review of research findings and literature on recent trends and business models", report to DG Employment, Social Affairs and Inclusion at the European Commission. 
Gratadour C. (2009), "Les expérimentations d'accompagnement renforcé de l'Unédic et de l'ANPE: Analyse du processus d'entrée en parcours d'accompagnement", Dares, Paris, Premières synthèses, $n^{\circ} 41.1$, octobre.

Gratadour C. and T. Le Barbanchon (2009), "Les expérimentations d'accompagnement renforcé de l'Unédic et de l'ANPE: contenu des accompagnements et opinion des bénéficiaires" Dares, Paris, Premières synthèses, $n^{\circ} 41.2$, octobre.

Grossman, S. and O. Hart (1986), "The Costs and Benefits of Ownership: A Theory of Vertical and Lateral Integration", Journal of Political Economy, 94, 691-719.

Hägglund, P., (2009), "Experimental evidence from intensified placement efforts among unemployed in Sweden", Institute for Labour Market Policy Evaluation (IFAU), WP 0916.

Hart, O., Shleifer, A., Vishny, R., (1997) "The Proper Scope of Government: Theory and an Application to Prisons", Quartely Journal of Economics, vol. 122(4), pp. 1127-61.

Heckman, J., Heinrich, C., Smith, J., (2002) "The Performance of Performance Standards", Journal of Human Resources 38(4), 778-811.

Heckman, J. and J. Smith (2004), "The Determinants of Participation in a Social Program: Evidence from a Prototypical Job Training Program", Journal of Labor Economics 22(2), 243-298.

Koning, P. and C. Heinrich (2010), "Cream-Skimming, Parking and Other Intended and Unintended Effects of Performance-Based Contracting in Social Welfare Services", IZA Discussion paper No. 4801.

Krug G. and Stephan G. (2011) "Is contracting-out intensified placement services more effective than in-house production? Evidence from a randomized field experiment". LASER Discussion Papers - Paper No. 51.

Lee W (2009), "Private Deception and the Rise of of Public Employment Offices in the United States, 1890-1930", in Studies of Labor Market Intermediation, David Autor eds., pp. $155-181$.

Lee D. (2009): “Training, Wages, and Sample Selection: Estimating Sharp Bounds on Treatment Effects", Review of Economic Studies, 76, 1071-1102. 
L'Humanité (2009), "Du fric sur le dos des chômeurs", n²0111 dated June 18, 2009.

Lundsgaard, J., (2002), "Competition and Efficiency in Publicly Funded Services", OECD Economic Studies No. 35, 2002/2, pp. 80-128.

McClellan M. (2011), "Reforming Payment to Healthcar Providers: The Key to Slowing Healthcare Spending Growth", Journal of Economic Perspectives, 25, 69-92.

McConnell, S., Burnwick, A., Perez-Johnson, I. and Winston, P. (2003) "Privatization in Practice: Case Studies of Contracting for TANF Case Management", Final Report prepared by Mathmatica Policy Research Inc. for the Office of the Assistant Secretary for Planning and Evaluation, U.S. Department of Health and Human Services, Washington DC. http://aspe.hhs.gov/hsp/privatization-rpt03/

Meyer B. (1995), "Lessons from the U.S. Unemployment Insurance Experiments", Journal of Economic Literature, 33(1), 91-131.

Rosholm, M., (2008), "Experimental Evidence on the Nature of the Danish Employment Miracle", Institute for the Study of Labor (IZA), Discussion Paper No. 3620.

Shleifer, A. (1998), "State Versus Private Ownership", Journal of Economic Perspectives, 12(4), 133-150.

Struyven L. (2004), "Design Choices in Market Competition for Employment Services for the Long-term Unemployed", OECD Social, employment and migration working papers, 21.

Struyven L. and G. Steurs (2002), "The Competitive Market for Employment Services in the Netherland", OECD Labour Market and Social Policy Occasional Paper.

van den Berg, G. and van der Klaauw, B. (2006), "Counseling and Monitoring of Unemployed Workers: Theory and Evidence from a Controlled Social Experiment", International Economic Review 47(3), 895936.

Vivès C. (2009), "Le recours aux opérateurs privés de placement dans le service public de l'emploi: étude et enjeux de la tarification de leurs prestations", in Barnay T., Legendre F. (eds), Emplois et politiques sociales. XXIX journées de l'association d'économie sociale, L'Harmattan, Paris, 207-219. 


\section{Appendix}

\section{Statistical appendix: interpretation of 2SLS in the three-treatment case}

This appendix clarifies the causal meaning of our Two Stage Least Square (2SLS) estimates through a direct extension of Angrist and Imbens LATE framework allowing for three treatments (including control), with random assignment to treatment but imperfect compliance.

There are three treatments $T \in\{0,1,2\}$ and people can be assigned to three groups $Z \in\{0,1,2\}$. Consider a variable of interest $Y$. Following Angrist and Imbens, there are in this setting nine potential outputs $Y(t, z) \quad(t, z) \in\{0,1,2\} \times\{0,1,2\}$. As in the LATE framework we introduce program entry decisions under assignment to $z$ : $T(z)$. Two assumptions of the LATE framework directly extend to this setting:

Assumption 1 Exclusion $Y(t, z)=Y(t)$ for all $t, z$

and

Assumption 2 Independence $Y(0), Y(1), Y(2), T(0), T(1), T(2) \perp Z$

We make a somewhat different Monotonicity Assumption than in the two treatment case:

\section{Assumption 3 Extended monotonicity}

$$
(T(2)=1)=(T(0)=1) \leq(T(1)=1)
$$

and

$$
(T(1)=2)=(T(0)=2) \leq(T(2)=2) .
$$

Assumption 3 implies that there are no "defiers" (who would enter treatment $k$ when assigned to group $j \neq k$, but not when assigned to group $k$ ). It also implies that those who enter treatment $k$ when assigned to group $j \neq k$ are exactly those who enter treatment $k$ when assigned to the third remaining group. For the assumption to hold, it is enough that the population contains only the following six types:

- never takers, such that: $T(0)=0, T(1)=0, T(2)=0$ 
- program 1 always takers: $T(0)=1, T(1)=1, T(2)=1$

- program 2 always takers: $T(0)=2, T(1)=2, T(2)=2$

- compliers: $T(0)=0, T(1)=1, T(2)=2$

- program 1 exclusive takers: $T(0)=0, T(1)=1, T(2)=0$

- program 2 exclusive takers: $T(0)=0, T(1)=0, T(2)=1$

The issue is how to interpret the 2SLS estimates of equation

$$
Y=a+c_{1}(T=1)+c_{2}(T=2)+u
$$

using $Z_{1}=(Z=1)$ and $Z_{2}=(Z=2)$ as instruments. Or, equivalently, how to interpret $c_{1}$ and $c_{2}$ as characterized by moment conditions

$$
E[u]=E\left[Z_{1} u\right]=E\left[Z_{2} u\right]=0 .
$$

Proposition 1 Under Assumption 1 , 2 and 3 ,

$$
c_{1}=E[y(1)-y(0) \mid(T(1)=1)-(T(0)=1)=1]
$$

and

$$
c_{2}=E[y(2)-y(0) \mid(T(2)=2)-(T(0)=2)=1] .
$$

$c_{1}$ and $c_{2}$ can thus be interpreted as Local Average Treatment Effects on compliers and program 1 exclusive takers (i.e. compliers to program 1), and on compliers and program 2 exclusive takers (i.e. compliers to program 2), respectively.

Proof 1 We have:

$$
T=T(0)+(T(1)-T(0)) Z_{1}+(T(2)-T(0)) Z_{2}
$$

which leads to

$(T=k)=(T(0)=k)+((T(1)=k)-(T(0)=k)) Z_{1}+((T(2)=k)-(T(0)=k)) Z_{2}, \quad k=1,2$

Moreover given Assumption 1, $Y$ can be written as

$$
Y=Y(0)+(Y(1)-Y(0))(T=1)+(Y(2)-Y(0))(T=2) .
$$


Thus

$$
\begin{aligned}
u= & Y(0)+(Y(1)-Y(0))(T(0)=1)+(Y(2)-Y(0))(T(0)=2)-c_{0}+ \\
& \left.Z_{1} \times\left[\left(Y(1)-Y(0)-c_{1}\right)((T(1)=1)-(T(0)=1))+\left(Y(2)-Y(0)-c_{2}\right)(T(2)=1)-(T(0)=1)\right)\right]+ \\
& \left.Z_{2} \times\left[\left(Y(1)-Y(0)-c_{1}\right)((T(1)=2)-(T(0)=2))+\left(Y(2)-Y(0)-c_{2}\right)(T(2)=2)-(T(0)=2)\right)\right] .
\end{aligned}
$$

The 2SLS orthogonality conditions and assumption 2 imply

$$
\left.E\left[\left(Y(1)-Y(0)-c_{1}\right)((T(1)=1)-(T(0)=1))+\left(Y(2)-Y(0)-c_{2}\right)(T(2)=1)-(T(0)=1)\right)\right]=0
$$

and

$$
\left.E\left[\left(Y(1)-Y(0)-c_{1}\right)((T(1)=2)-(T(0)=2))+\left(Y(2)-Y(0)-c_{2}\right)(T(2)=2)-(T(0)=2)\right)\right]=0 .
$$

These two equations can be solved in $c_{1}$ and $c_{2}$. Without further assumptions, $c_{k}$ is a linear combination of $E[Y(1)-Y(0) \mid(T(1)=1)-(T(0)=1)=1], E[Y(1)-Y(0) \mid(T(1)=$ $2)-(T(0)=2)=1], E[Y(2)-Y(0) \mid(T(2)=1)-(T(0)=1)=1]$, and $E[Y(2)-$ $Y(0) \mid(T(2)=2)-(T(0)=2)=1]$, which is hard to interpret. However, under assumption 3, the two equations greatly simplify to

$$
\left(E[Y(1)-Y(0) \mid(T(1)=1)-(T(0)=1)=1]-c_{1}\right) P((T(1)=1)-(T(0)=1)=1)=0
$$

and

$$
\left(E[Y(2)-Y(0) \mid(T(2)=2)-(T(0)=2)=1]-c_{2}\right) P((T(2)=2)-(T(0)=1)=2)=0,
$$

which yields proposition 1 . 


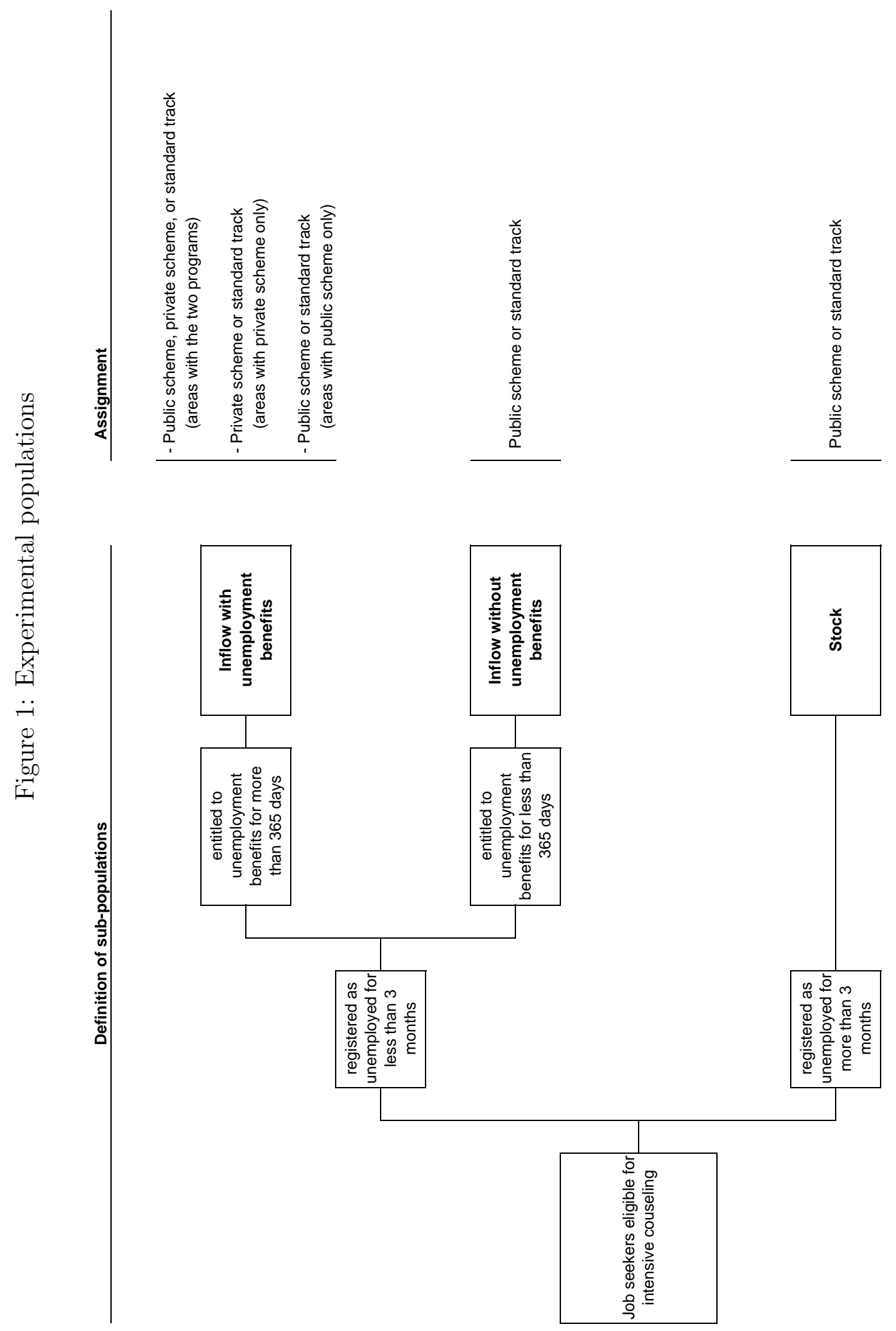


0
0
00
0
0
0
0
0
0
0
0
0
0
0
0
0
0
0
0
0
0
0
0
0
0
01
0
0
0
00
0
0

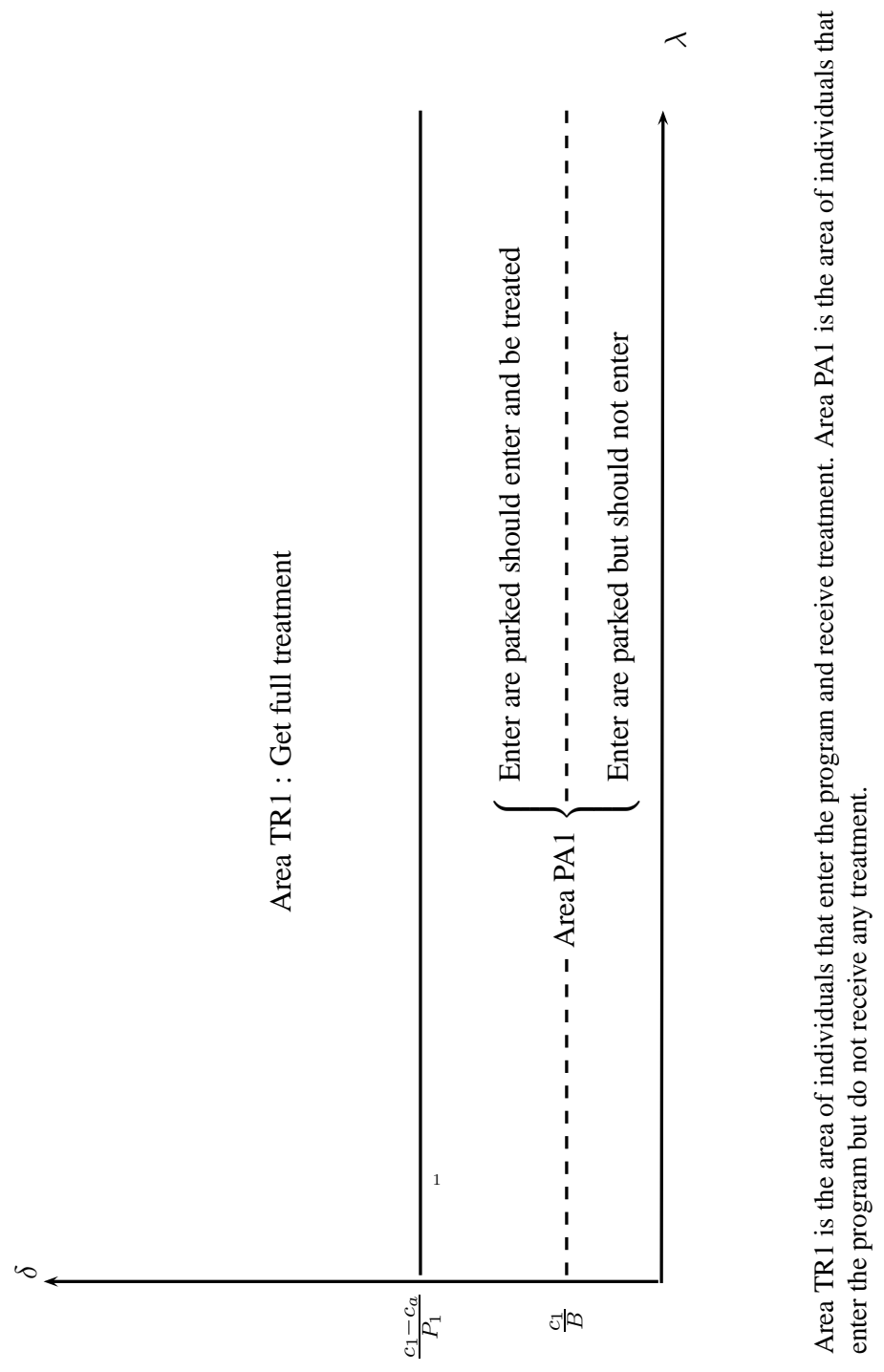


0
0
7
0
0
0
0
0
0
0
0
0
0
0
0
0
0
0
0
0
0
0
0
0
0
0
0
0
0
0
0
0
0

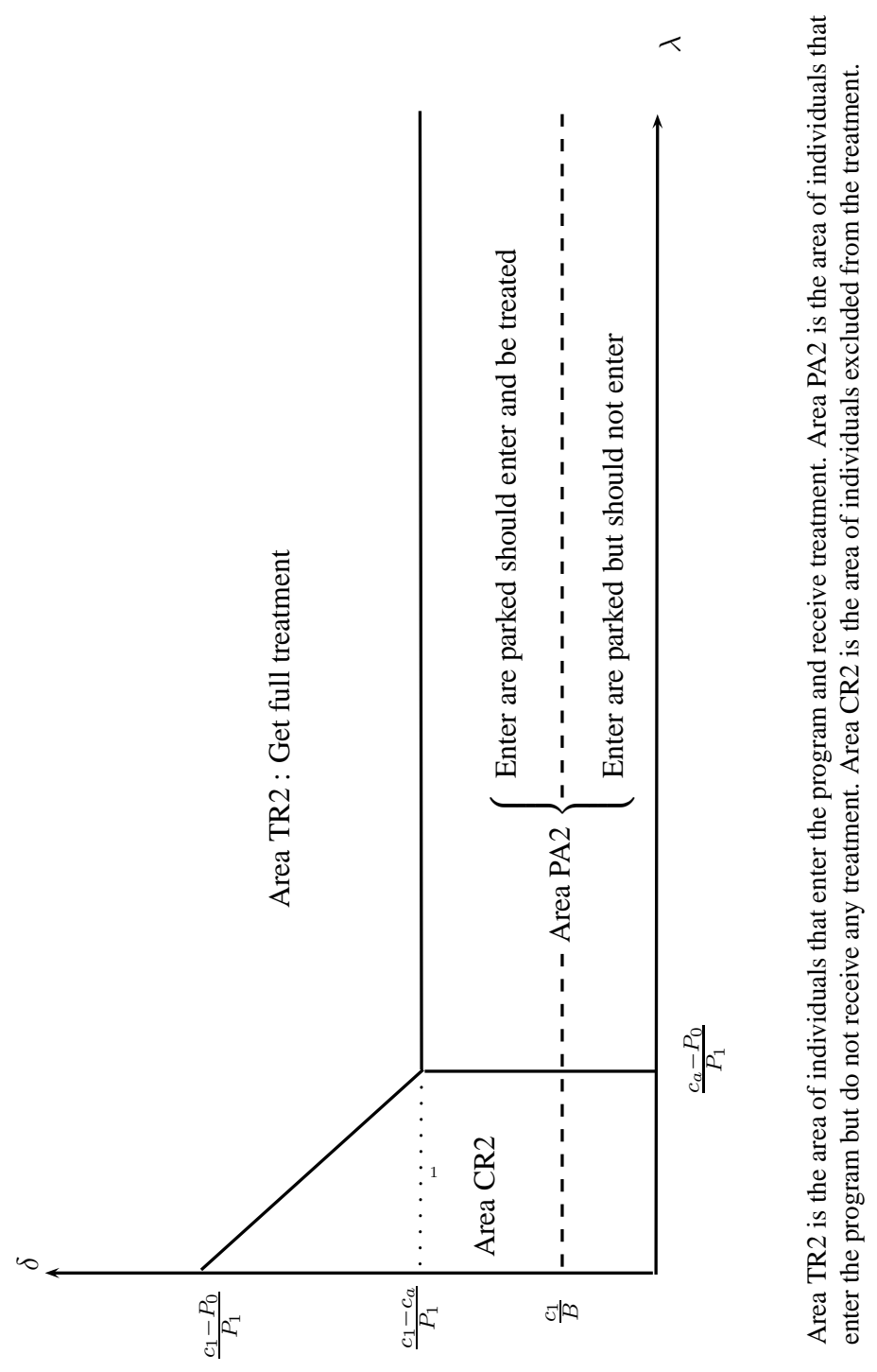


0
0
0
0
0
0
0
0
0
0
0
0
0
0
0
0
0
0
00
0
0
0
0
0
0
0
0
0
0
0
0
0
0
0
0
0
0
0
0
0
0
0
0
0
0
0
01

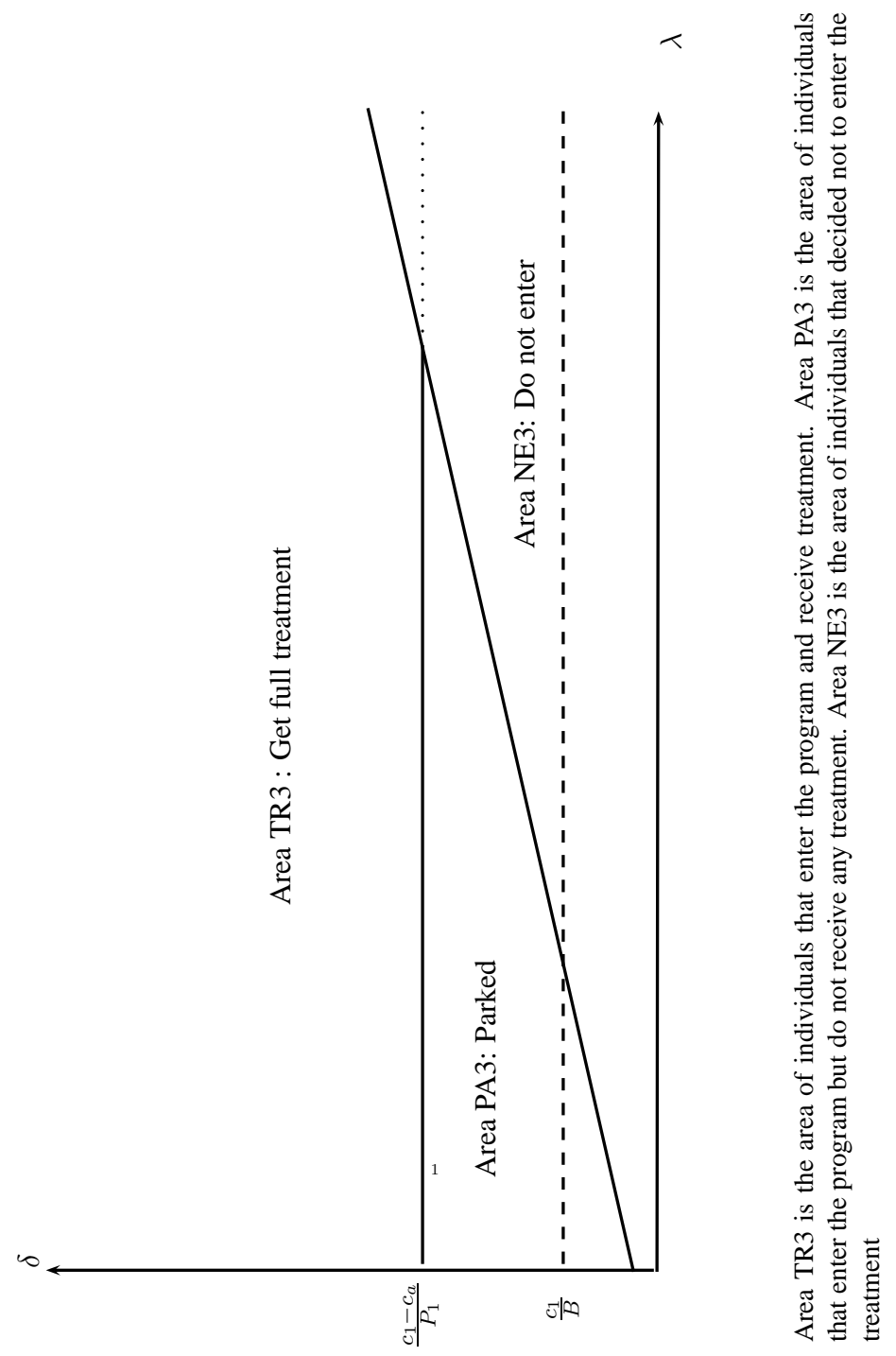




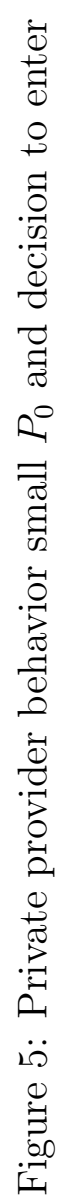

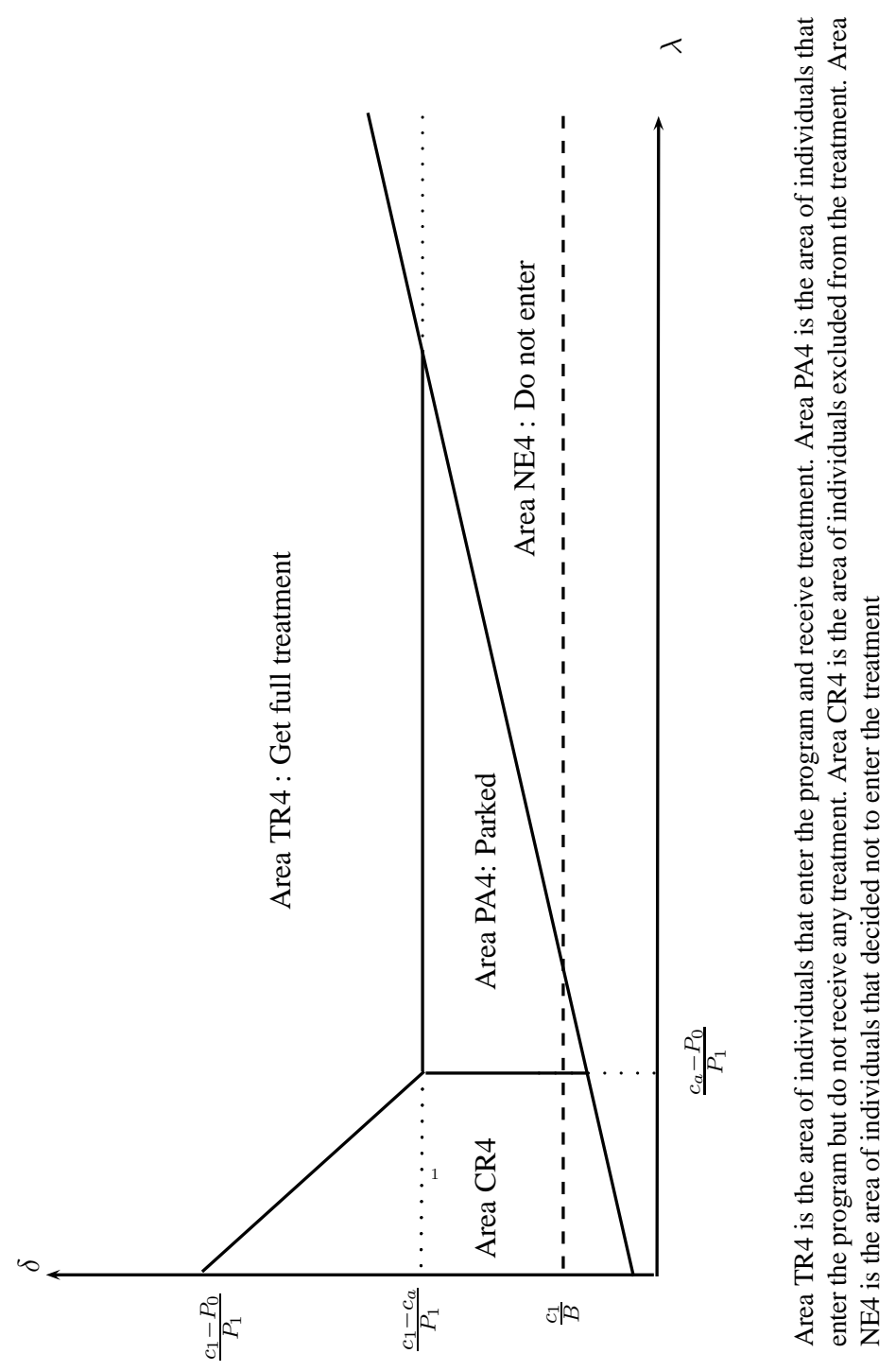




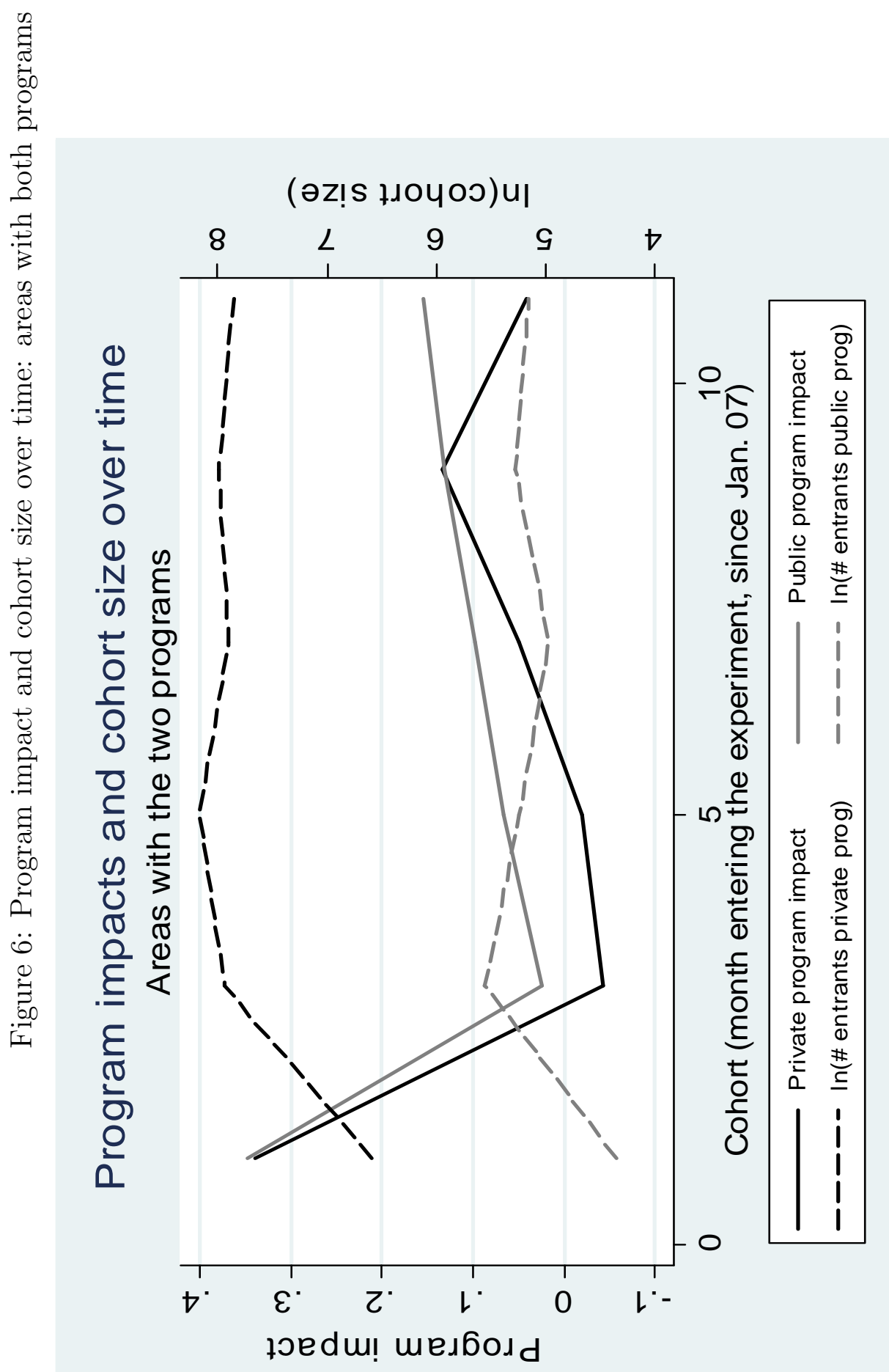




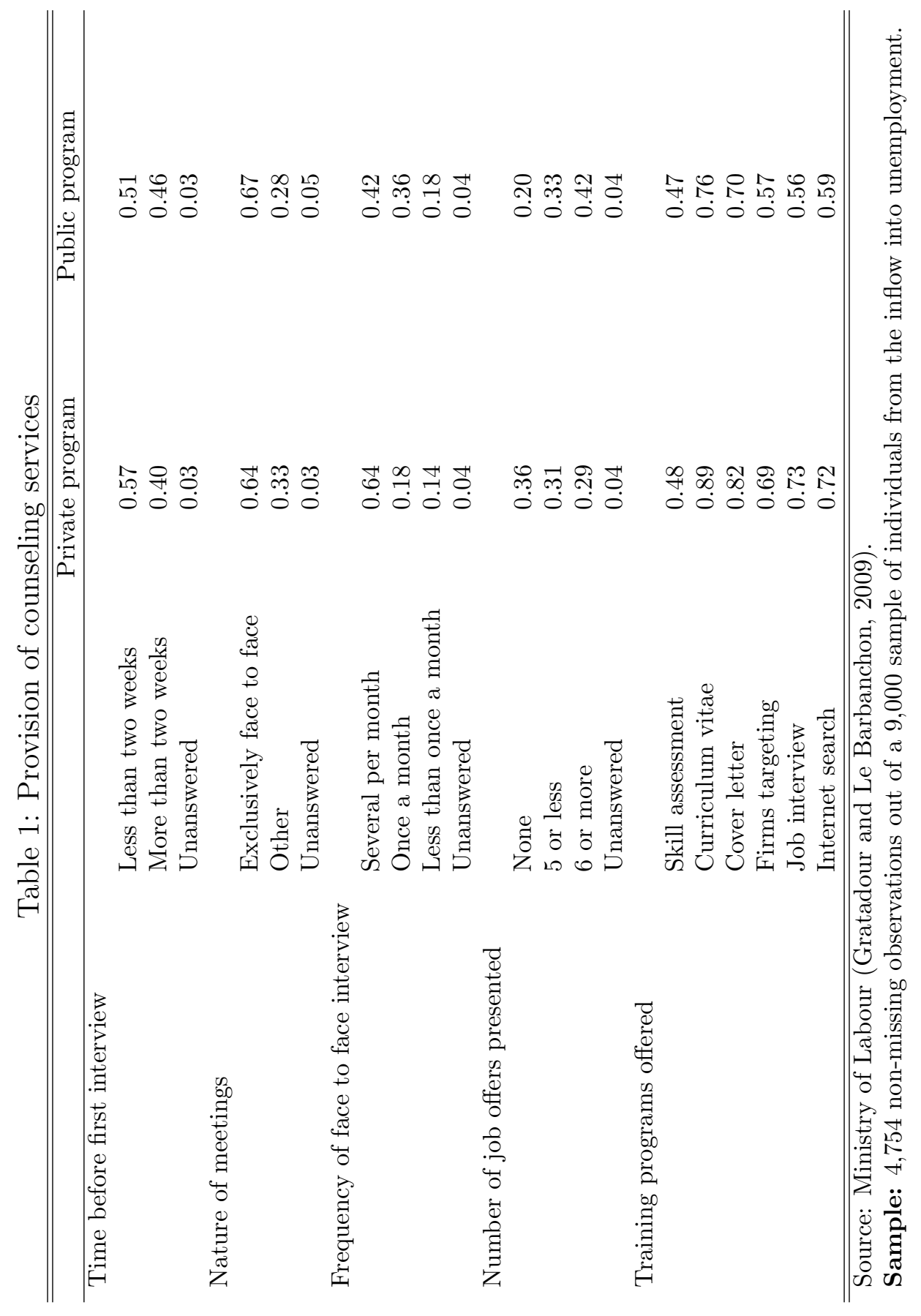




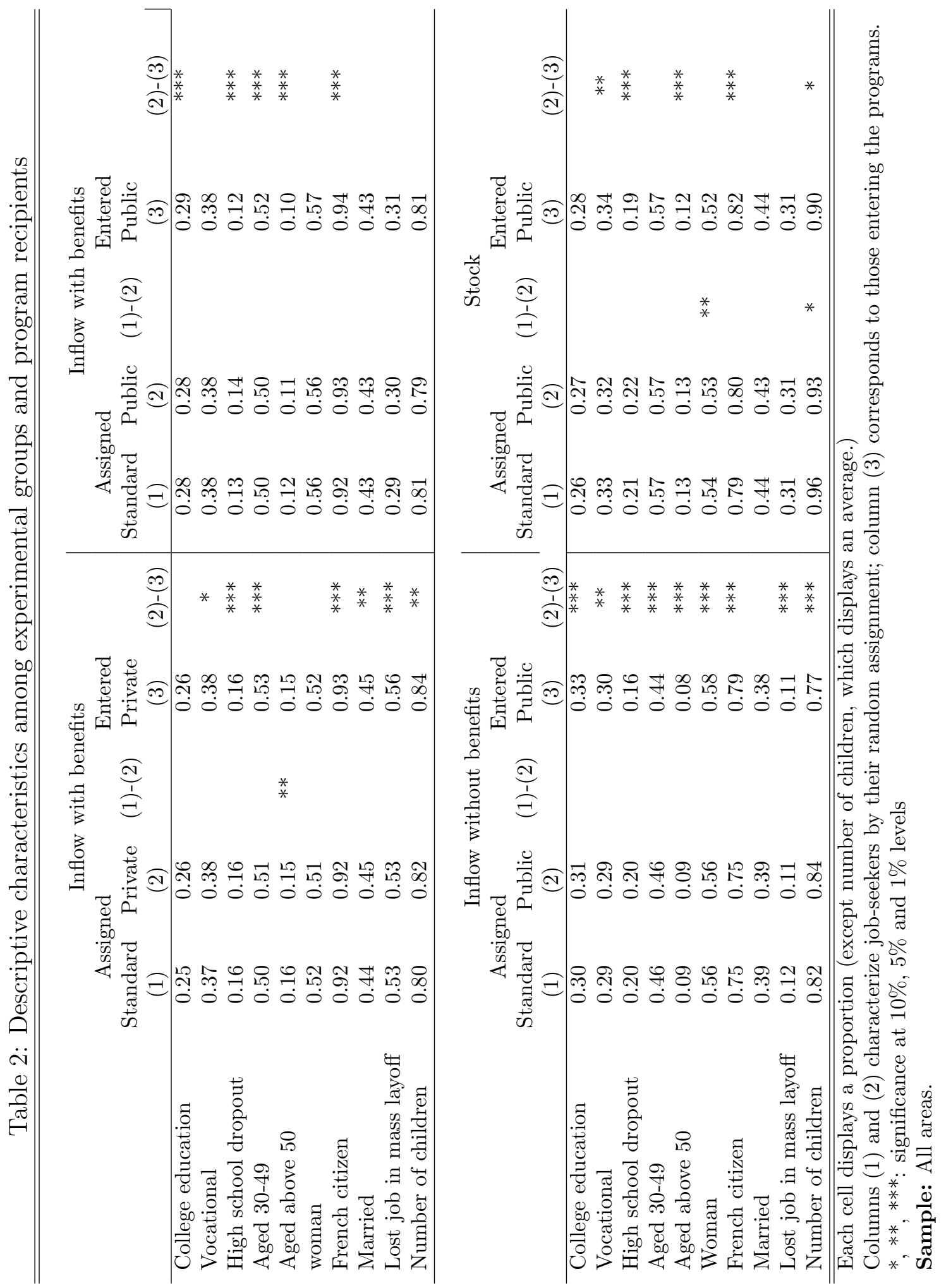




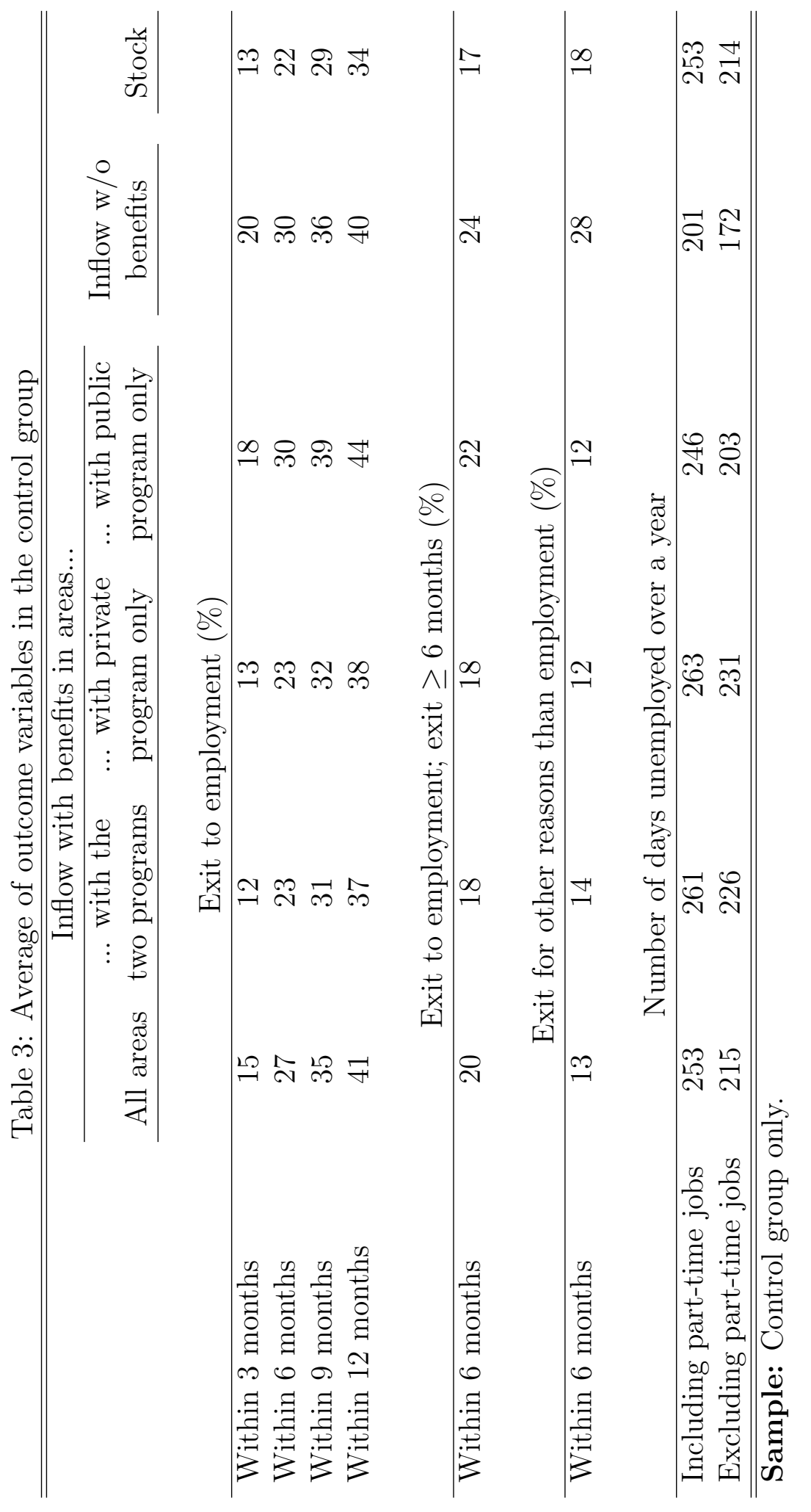




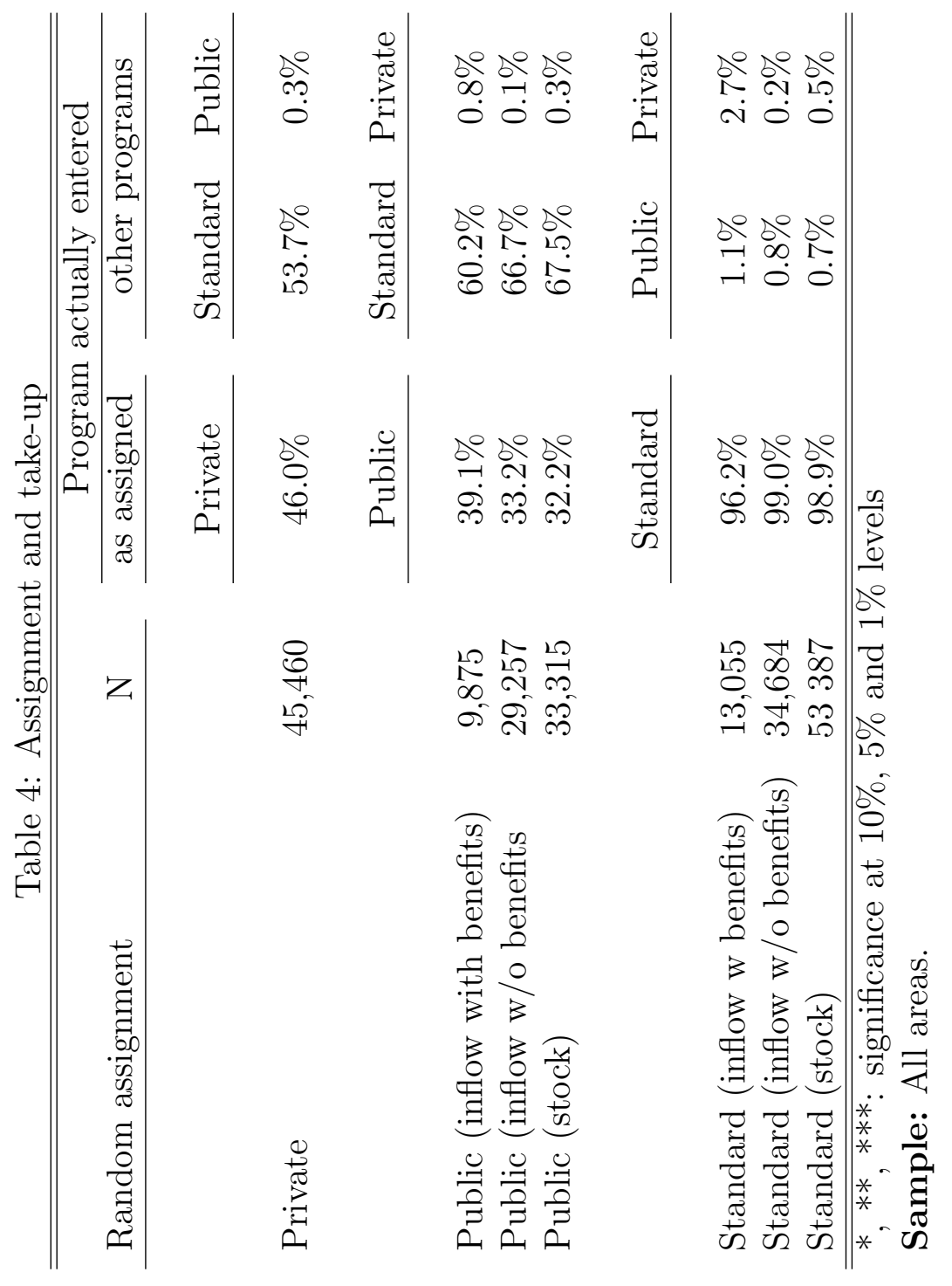


Table 5: Program participation

\begin{tabular}{|c|c|c|c|c|c|c|}
\hline \multirow[b]{3}{*}{ Intercept } & \multirow{3}{*}{$\begin{array}{c}\text { Private program } \\
\\
0.344^{* * *} \\
(0.013)\end{array}$} & \multicolumn{3}{|c|}{ Public program } & \multirow{2}{*}{\multicolumn{2}{|c|}{$\begin{array}{c}\text { Public and private programs } \\
\text { (inflow with benefits, } \\
\text { areas with } 2 \text { programs) }\end{array}$}} \\
\hline & & \multirow{2}{*}{$\begin{array}{l}\text { inflow with } \\
\text { benefits } \\
0.338^{* * *} \\
(0.023)\end{array}$} & \multirow{2}{*}{$\begin{array}{l}\text { inflow w/o } \\
\text { benefits } \\
0.295^{* * *} \\
(0.013)\end{array}$} & \multirow{2}{*}{$\begin{array}{l}\text { Stock } \\
\\
0.296^{* * *} \\
(0.017)\end{array}$} & & \\
\hline & & & & & $\begin{array}{c}0.321^{* * *} \\
(0.009)\end{array}$ & $\begin{array}{c}0.285^{* * *} \\
(0.036)\end{array}$ \\
\hline College education & $\begin{array}{l}-0.004 \\
(0.009)\end{array}$ & $\begin{array}{c}0.004 \\
(0.016)\end{array}$ & $\begin{array}{l}0.019^{*} \\
(0.011)\end{array}$ & $\begin{array}{l}-0.002 \\
(0.012)\end{array}$ & & $\begin{array}{l}-0.007 \\
(0.027)\end{array}$ \\
\hline Vocational & $\begin{array}{c}0.008 \\
(0.009)\end{array}$ & $\begin{array}{l}-0.018 \\
(0.015)\end{array}$ & $\begin{array}{l}0.008 \\
(0.011)\end{array}$ & $\begin{array}{l}0.001 \\
(0.012)\end{array}$ & & $\begin{array}{l}-0.025 \\
(0.027)\end{array}$ \\
\hline High school dropout & $\begin{array}{c}-0.025 * * \\
(0.011)\end{array}$ & $\begin{array}{c}-0.053^{* * *} \\
(0.019)\end{array}$ & $\begin{array}{c}-0.050 * * * \\
(0.012)\end{array}$ & $\begin{array}{c}-0.043^{* * *} \\
(0.013)\end{array}$ & & $\begin{array}{l}-0.030 \\
(0.031)\end{array}$ \\
\hline Aged $30-49$ & $\begin{array}{c}0.033^{* * *} \\
(0.008)\end{array}$ & $\begin{array}{l}0.025^{*} \\
(0.013)\end{array}$ & $\begin{array}{c}-0.018^{* *} \\
(0.009)\end{array}$ & $\begin{array}{c}0.000 \\
(0.010)\end{array}$ & & $\begin{array}{c}0.011 \\
(0.023)\end{array}$ \\
\hline Aged above 50 & $\begin{array}{c}0.016 \\
(0.010)\end{array}$ & $\begin{array}{c}-0.035^{*} \\
(0.018)\end{array}$ & $\begin{array}{l}-0.059^{* * *} \\
(0.013)\end{array}$ & $\begin{array}{c}-0.028^{* *} \\
(0.014)\end{array}$ & & $\begin{array}{l}-0.040 \\
(0.030)\end{array}$ \\
\hline Woman & $\begin{array}{c}0.003 \\
(0.007)\end{array}$ & $\begin{array}{c}0.004 \\
(0.011)\end{array}$ & $\begin{array}{c}0.021 * * * \\
(0.008)\end{array}$ & $\begin{array}{c}-0.014^{*} \\
(0.008)\end{array}$ & & $\begin{array}{l}-0.001 \\
(0.019)\end{array}$ \\
\hline Foreigner & $\begin{array}{c}0.077^{* * *} \\
(0.009)\end{array}$ & $\begin{array}{c}0.076^{* * *} \\
(0.018)\end{array}$ & $\begin{array}{c}0.056^{* * *} \\
(0.009)\end{array}$ & $\begin{array}{c}0.041^{* * *} \\
(0.011)\end{array}$ & & $\begin{array}{l}0.049^{*} \\
(0.026)\end{array}$ \\
\hline Married & $\begin{array}{c}0.006 \\
(0.007)\end{array}$ & $\begin{array}{c}0.003 \\
(0.013)\end{array}$ & $\begin{array}{c}0.026 * * * \\
(0.009)\end{array}$ & $\begin{array}{c}0.023^{* *} \\
(0.009)\end{array}$ & & $\begin{array}{c}0.010 \\
(0.022)\end{array}$ \\
\hline Lost job in mass layoff & $\begin{array}{l}0.055^{* * *} \\
(0.007)\end{array}$ & $\begin{array}{l}-0.011 \\
(0.012)\end{array}$ & $\begin{array}{c}-0.024^{* *} \\
(0.011)\end{array}$ & $\begin{array}{l}-0.008 \\
(0.009)\end{array}$ & & $\begin{array}{c}0.013 \\
(0.019)\end{array}$ \\
\hline Number of children & $\begin{array}{c}0.003 \\
(0.003)\end{array}$ & $\begin{array}{c}0.004 \\
(0.006)\end{array}$ & $\begin{array}{l}-0.006^{*} \\
(0.003)\end{array}$ & $\begin{array}{l}-0.003 \\
(0.004)\end{array}$ & & $\begin{array}{l}-0.001 \\
(0.009)\end{array}$ \\
\hline $\begin{array}{l}\text { Assigned to private } \\
\text { programm (private) }\end{array}$ & & & & & $\begin{array}{c}0.108^{* * *} \\
(0.010)\end{array}$ & $\begin{array}{l}0.035 \\
(0.039)\end{array}$ \\
\hline Private $\times$ College education & & & & & & $\begin{array}{l}0.006 \\
(0.029)\end{array}$ \\
\hline Private $\times$ Vocational & & & & & & $\begin{array}{c}0.029 \\
(0.029)\end{array}$ \\
\hline Private $\times$ High school dropout & & & & & & $\begin{array}{c}0.019 \\
(0.033)\end{array}$ \\
\hline Private $\times$ Aged $30-49$ & & & & & & $\begin{array}{c}0.021 \\
(0.025)\end{array}$ \\
\hline Private $\times$ Aged above 50 & & & & & & $\begin{array}{l}0.053^{*} \\
(0.032)\end{array}$ \\
\hline Private $\times$ Woman & & & & & & $\begin{array}{c}0.005 \\
(0.020)\end{array}$ \\
\hline Private $\times$ Foreigner & & & & & & $\begin{array}{c}0.014 \\
(0.027)\end{array}$ \\
\hline Private $\times$ Married & & & & & & $\begin{array}{l}-0.000 \\
(0.023)\end{array}$ \\
\hline Private $\times$ Lost job in mass layoff & & & & & & $\begin{array}{c}0.046^{* *} \\
(0.021)\end{array}$ \\
\hline Private $\times$ Number of children & & & & & & $\begin{array}{c}0.002 \\
(0.010)\end{array}$ \\
\hline Observations & 45,460 & 9,875 & 29,257 & 33,315 & 39,412 & 39,412 \\
\hline R-squared & 0.466 & 0.407 & 0.342 & 0.317 & 0.421 & 0.426 \\
\hline
\end{tabular}




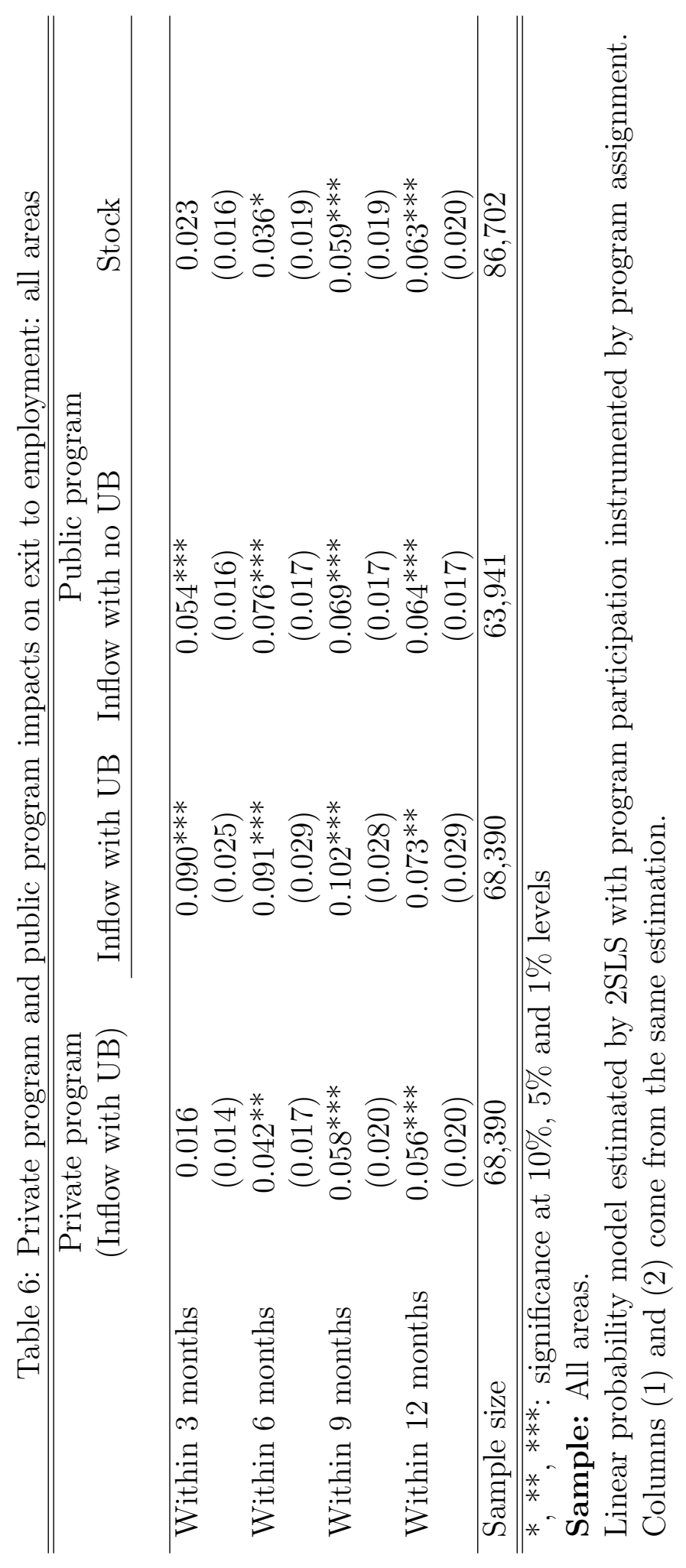




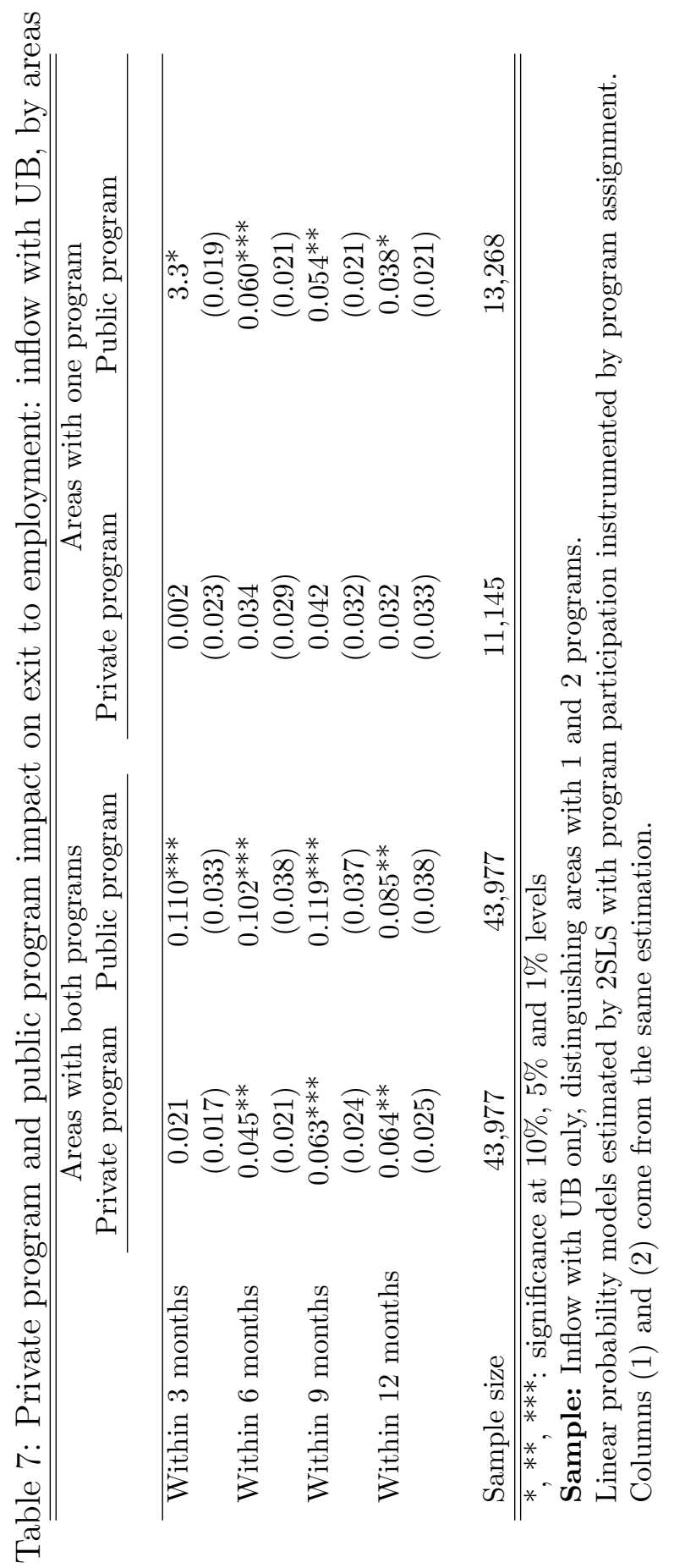




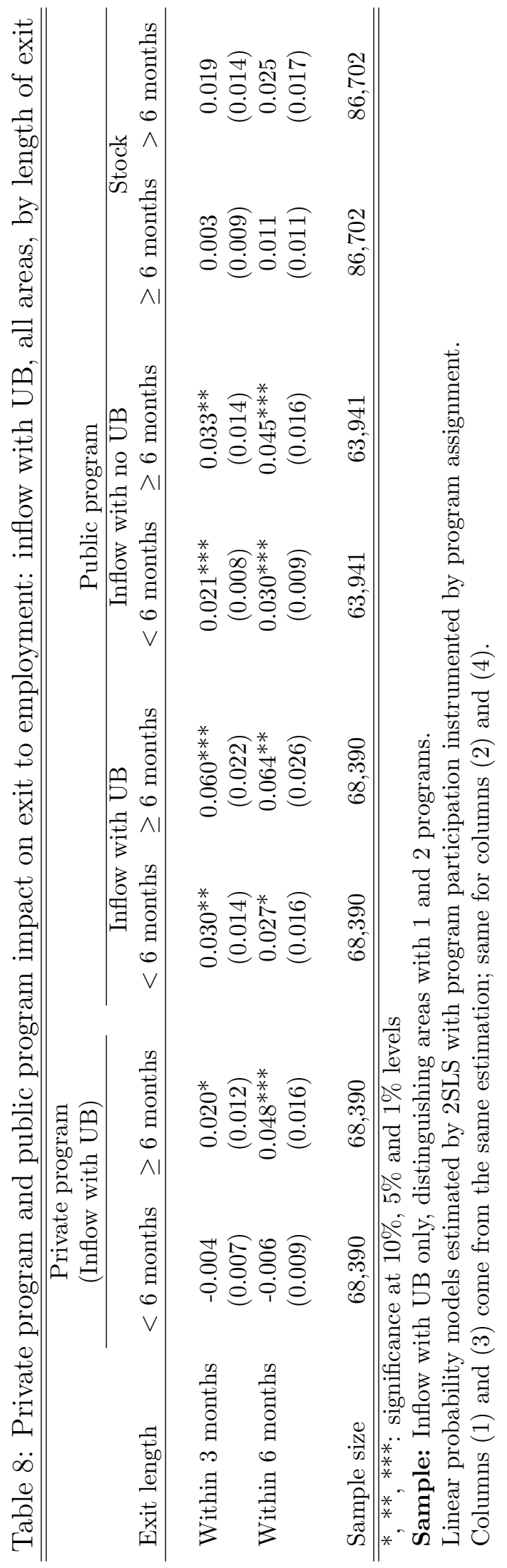




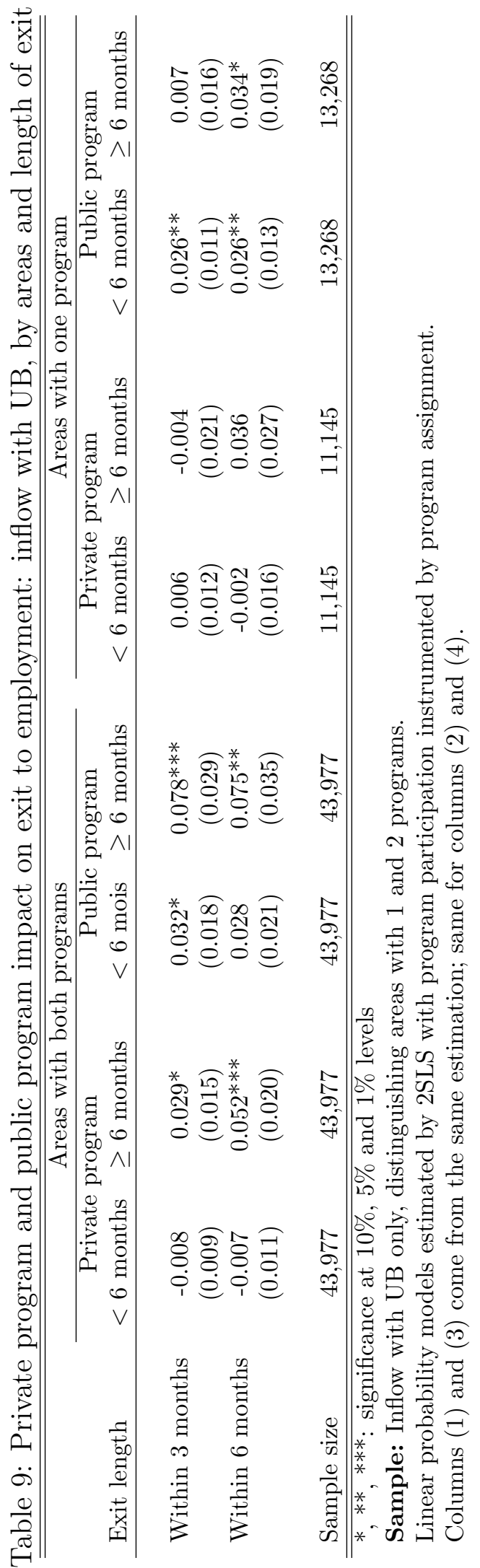


Table 10: Heterogeneity in program impacts. Exit to employment within 6 months

\begin{tabular}{|c|c|c|c|c|c|}
\hline & $\begin{array}{r}\text { Inflow } \\
\text { two programs }\end{array}$ & $\begin{array}{c}\text { with unemployment } \\
\text { areas with } \\
\text { private program }\end{array}$ & $\begin{array}{l}\text { benefits, } \\
\text { public program }\end{array}$ & $\begin{array}{l}\text { Inflow } \\
\text { without } \\
\text { benefits }\end{array}$ & Stock \\
\hline Intercept & $\begin{array}{c}0.295^{* * *} \\
(0.021)\end{array}$ & $\begin{array}{c}0.299 * * * \\
(0.034)\end{array}$ & $\begin{array}{c}0.398 * * * \\
(0.015)\end{array}$ & $\begin{array}{c}0.339 * * * \\
(0.009)\end{array}$ & $\begin{array}{c}0.287^{* * *} \\
(0.010)\end{array}$ \\
\hline College education & $\begin{array}{c}0.061^{* * *} \\
(0.020)\end{array}$ & $\begin{array}{c}0.095^{* * *} \\
(0.036)\end{array}$ & $\begin{array}{c}0.104^{* * *} \\
(0.015)\end{array}$ & $\begin{array}{c}0.125^{* * *} \\
(0.009)\end{array}$ & $\begin{array}{c}0.076^{* * *} \\
(0.009)\end{array}$ \\
\hline High school graduate & $\begin{array}{l}-0.007 \\
(0.022)\end{array}$ & $\begin{array}{c}0.009 \\
(0.037)\end{array}$ & $\begin{array}{c}0.051^{* * *} \\
(0.016)\end{array}$ & $\begin{array}{c}0.044^{* * *} \\
(0.010)\end{array}$ & $\begin{array}{c}0.038^{* * *} \\
(0.010)\end{array}$ \\
\hline Aged $30-49$ & $\begin{array}{c}-0.056^{* * *} \\
(0.020)\end{array}$ & $\begin{array}{c}-0.088^{* * *} \\
(0.033)\end{array}$ & $\begin{array}{l}-0.121 * * * \\
(0.014)\end{array}$ & $\begin{array}{c}-0.100^{* * *} \\
(0.008)\end{array}$ & $\begin{array}{c}-0.099^{* * *} * \\
(0.009)\end{array}$ \\
\hline Aged above 50 & $\begin{array}{c}-0.166^{* * *} \\
(0.023)\end{array}$ & $\begin{array}{l}-0.151^{* * *} \\
(0.040)\end{array}$ & $\begin{array}{l}-0.199^{* * *} \\
(0.019)\end{array}$ & $\begin{array}{l}-0.149^{* * *} \\
(0.013)\end{array}$ & $\begin{array}{c}-0.178^{* * *} \\
(0.011)\end{array}$ \\
\hline Woman & $\begin{array}{l}-0.048^{* * *} \\
(0.017)\end{array}$ & $\begin{array}{c}-0.066 * * \\
(0.028)\end{array}$ & $\begin{array}{l}-0.097^{* * *} \\
(0.013)\end{array}$ & $\begin{array}{l}-0.049^{* * *} \\
(0.008)\end{array}$ & $\begin{array}{l}-0.020^{* * * *} \\
(0.008)\end{array}$ \\
\hline $\begin{array}{l}\text { Treated by private } \\
\text { programm (Tprivate) }\end{array}$ & $\begin{array}{c}0.069 \\
(0.058)\end{array}$ & $\begin{array}{c}0.039 \\
(0.073)\end{array}$ & & & \\
\hline Tprivate $\times$ College education & $\begin{array}{c}0.043 \\
(0.050)\end{array}$ & $\begin{array}{c}0.025 \\
(0.071)\end{array}$ & & & \\
\hline Tprivate $\times$ High school graduate & $\begin{array}{c}0.071 \\
(0.057)\end{array}$ & $\begin{array}{c}0.055 \\
(0.076)\end{array}$ & & & \\
\hline Tprivate $\times$ Aged 30-49 & $\begin{array}{c}-0.153^{* * *} \\
(0.054)\end{array}$ & $\begin{array}{l}-0.020 \\
(0.068)\end{array}$ & & & \\
\hline Tprivate $\times$ Aged above 50 & $\begin{array}{l}-0.057 \\
(0.062)\end{array}$ & $\begin{array}{l}-0.058 \\
(0.082)\end{array}$ & & & \\
\hline Tprivate $\times$ Woman & $\begin{array}{c}0.064 \\
(0.043)\end{array}$ & $\begin{array}{c}0.017 \\
(0.058)\end{array}$ & & & \\
\hline $\begin{array}{l}\text { Treated by public } \\
\text { programm (Tpublic) }\end{array}$ & $\begin{array}{l}0.169^{*} \\
(0.099)\end{array}$ & & $\begin{array}{c}0.036 \\
(0.051)\end{array}$ & $\begin{array}{c}0.087 * * \\
(0.038)\end{array}$ & $\begin{array}{l}0.084^{*} \\
(0.047)\end{array}$ \\
\hline Tpublic $\times$ College education & $\begin{array}{c}0.003 \\
(0.088)\end{array}$ & & $\begin{array}{c}0.048 \\
(0.049)\end{array}$ & $\begin{array}{c}0.002 \\
(0.038)\end{array}$ & $\begin{array}{l}-0.005 \\
(0.045)\end{array}$ \\
\hline Tpublic $\times$ High school graduate & $\begin{array}{c}0.079 \\
(0.100)\end{array}$ & & $\begin{array}{l}-0.041 \\
(0.053)\end{array}$ & $\begin{array}{l}-0.038 \\
(0.044)\end{array}$ & $\begin{array}{c}0.017 \\
(0.049)\end{array}$ \\
\hline Tpublic $\times$ Aged $30-49$ & $\begin{array}{l}-0.148 \\
(0.090)\end{array}$ & & $\begin{array}{c}0.021 \\
(0.046)\end{array}$ & $\begin{array}{c}0.011 \\
(0.035)\end{array}$ & $\begin{array}{l}-0.011 \\
(0.044)\end{array}$ \\
\hline Tpublic $\times$ Aged above 50 & $\begin{array}{l}-0.044 \\
(0.115)\end{array}$ & & $\begin{array}{c}0.013 \\
(0.067)\end{array}$ & $\begin{array}{l}-0.078 \\
(0.063)\end{array}$ & $\begin{array}{c}0.018 \\
(0.058)\end{array}$ \\
\hline Tpublic $\times$ Woman & $\begin{array}{l}-0.023 \\
(0.076)\end{array}$ & & $\begin{array}{c}0.020 \\
(0.042)\end{array}$ & $\begin{array}{l}-0.006 \\
(0.034)\end{array}$ & $\begin{array}{c}-0.095^{* *} \\
(0.037)\end{array}$ \\
\hline Observations & 43,977 & 11,145 & 13,268 & 63,941 & 86,702 \\
\hline
\end{tabular}

Sample: All, by populations and areas.

Linear probability models estimated by 2 SLS with program participation instrumented by program assignment (interacted with covariates). 


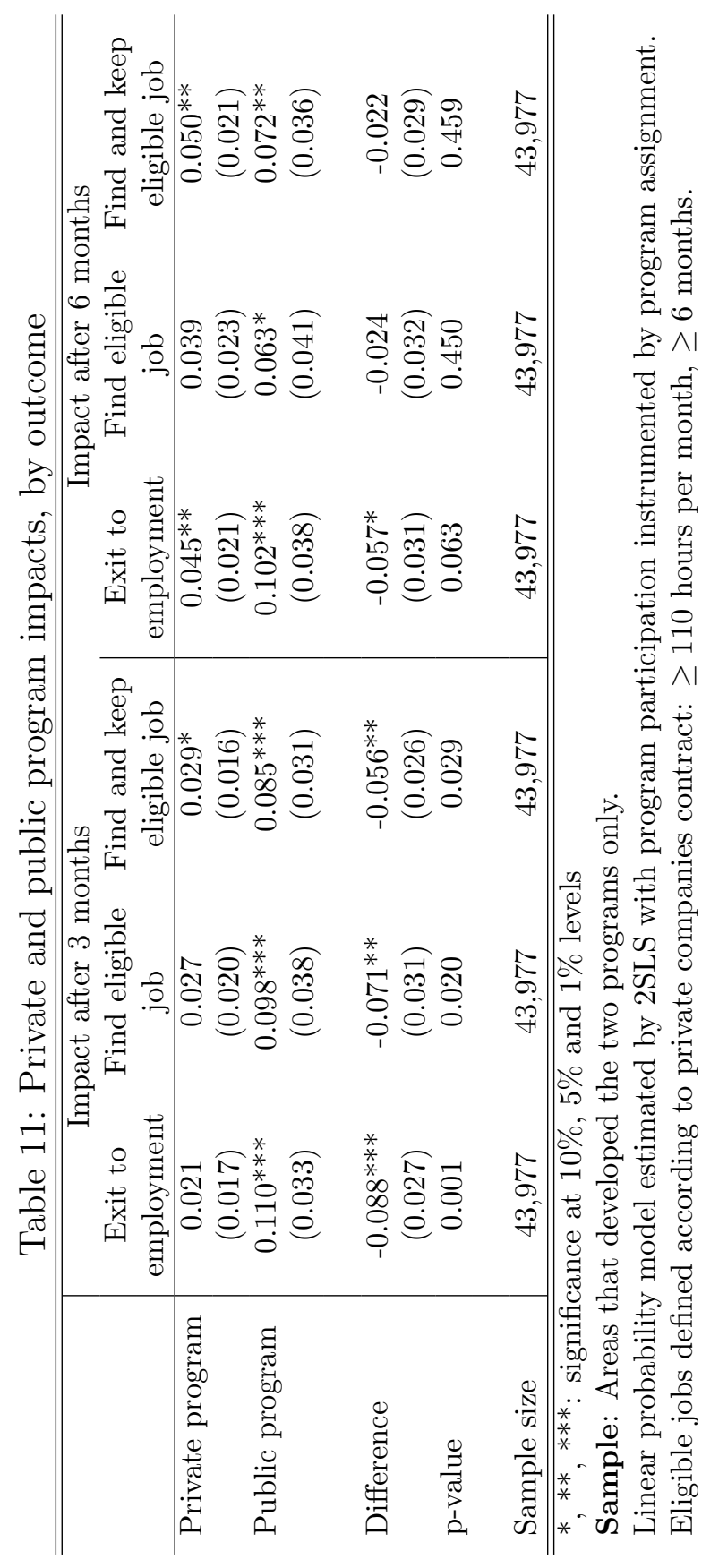




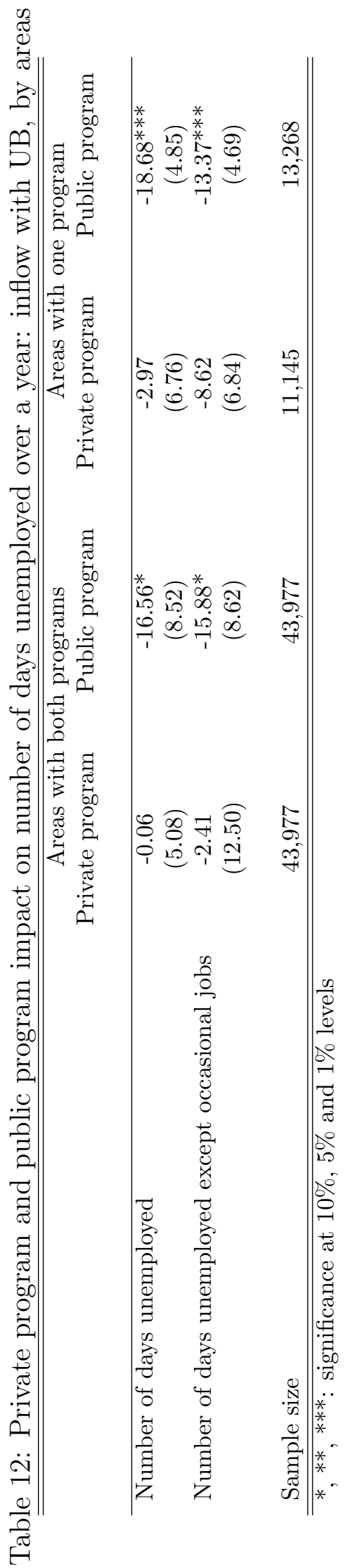




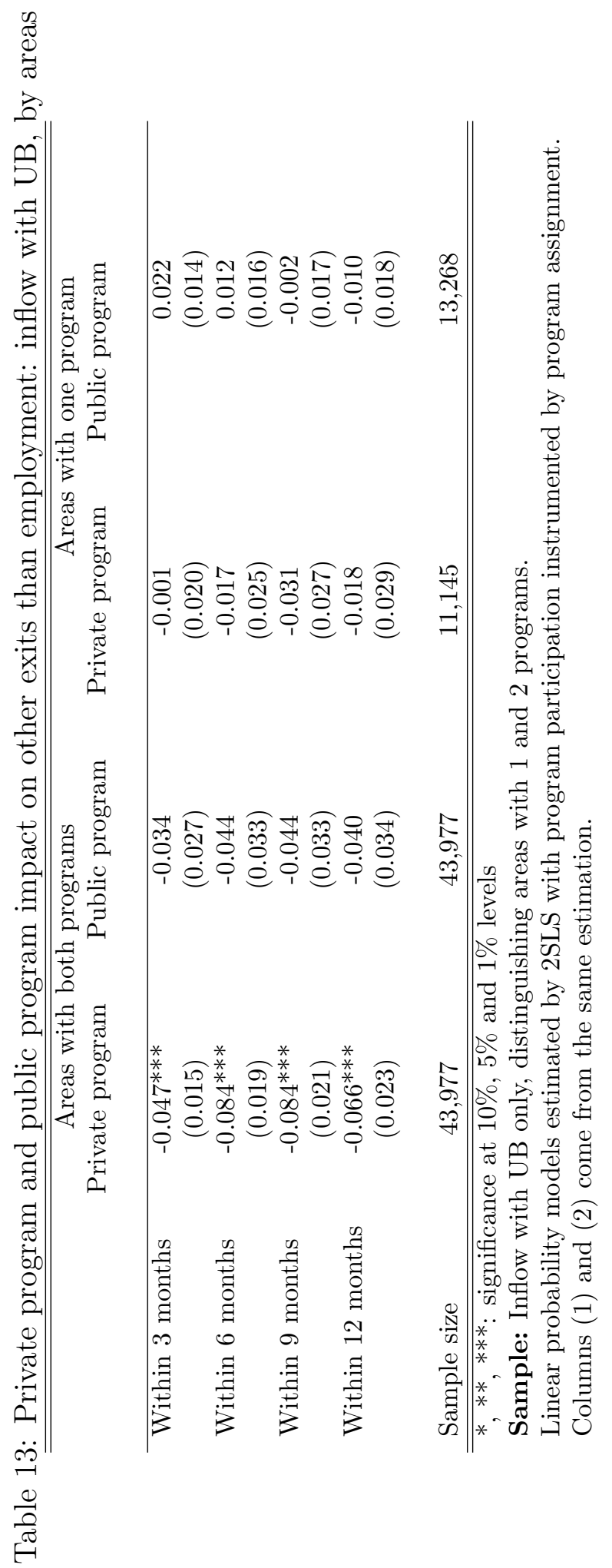




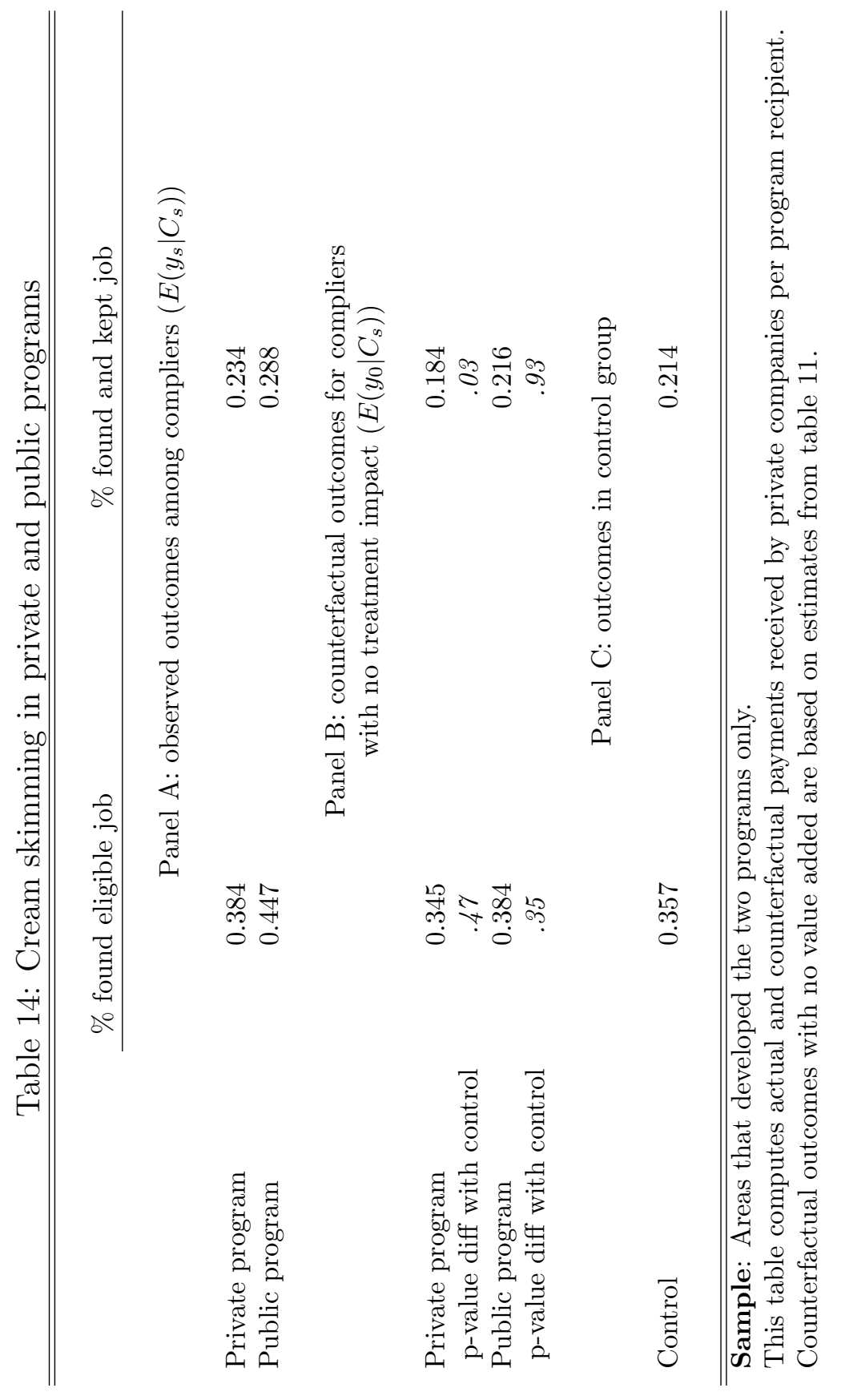




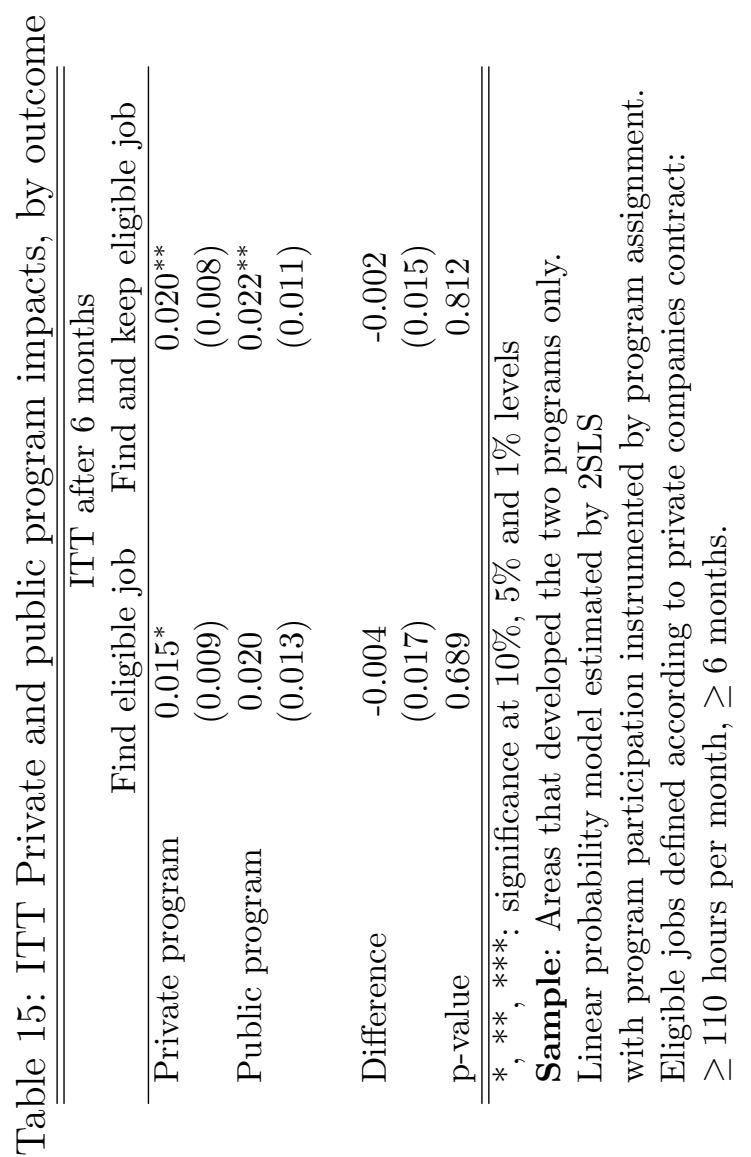

